\title{
Therapeutic Peptides Targeting PPI in Clinical Development: Overview, Mechanism of Action and Perspectives
}

\author{
Walter Cabri *, Paolo Cantelmi, Dario Corbisiero, Tommaso Fantoni, Lucia Ferrazzano, \\ Giulia Martelli, Alexia Mattellone and Alessandra Tolomelli*
}

Department of Chemistry "Giacomo Ciamician", Alma Mater Studiorum University of Bologna, Bologna, Italy

\section{OPEN ACCESS}

Edited by:

M. Angeles Jimenez, Instituto de Química Física Rocasolano (IQFR), Spain

Reviewed by:

Alemayehu A. Gorfe, University of Texas Health Science Center at Houston, United States

Efstratios Stratikos,

National and Kapodistrian University of

Athens, Greece

*Correspondence:

Alessandra Tolomelli

alessandra.tolomelli@unibo.it Walter Cabri

walter.cabri@unibo.it

Specialty section:

This article was submitted to Molecular Recognition,

a section of the journal

Frontiers in Molecular Biosciences

Received: 19 April 2021 Accepted: 01 June 2021 Published: 14 June 2021

Citation:

Cabri W, Cantelmi $P$, Corbisiero $D$, Fantoni T, Ferrazzano L, Martelli G, Mattellone A and Tolomelli A (2021)

Therapeutic Peptides Targeting PPI in

Clinical Development: Overview,

Mechanism of Action

and Perspectives.

Front. Mol. Biosci. 8:697586.

doi: 10.3389/fmolb.2021.697586
Targeting protein-protein interactions (PPIs) has been recently recognized as an emerging therapeutic approach for several diseases. Up today, more than half a million PPI dysregulations have been found to be involved in pathological events. The dynamic nature of these processes and the involvement of large protein surfaces discouraged anyway the scientific community in considering them promising therapeutic targets. More recently peptide drugs received renewed attention since drug discovery has offered a broad range of structural diverse sequences, moving from traditionally endogenous peptides to sequences possessing improved pharmaceutical profiles. About 70 peptides are currently on the marked but several others are in clinical development. In this review we want to report the update on these novel APIs, focusing our attention on the molecules in clinical development, representing the direct consequence of the drug discovery process of the last 10 years. The comprehensive collection will be classified in function of the structural characteristics (native, analogous, heterologous) and on the basis of the therapeutic targets. The mechanism of interference on PPI will also be reported to offer useful information for novel peptide design.

Keywords: therapeutics, clinical trials, PPI, peptides, pharmacokinetic, GLP-1, cancer, SPPS

\section{INTRODUCTION}

In the progression of many pathological states, protein-protein interactions (PPIs) play the fundamental role of mediators of signal transmission and for this reason they represent optimal targets for drug discovery.

The size of the human interactome, the complex network of protein interactions, has been estimated to involve about 650,000 relevant contacts (Stumpf et al., 2008) that regulate all biological events and are responsible, when dysregulated, of a great number of pathological diseases. The dynamic nature of PPI and the large contact area that is often required between the partners (approximately 1,000-4,000 $\AA$ ) have discouraged in the past to consider them as interesting targets. Small molecule drugs indeed are able to inhibit only interactions involving a binding area from 300 to $1,000 \AA$ (Jones and Thornton, 1996) and PPI often lack of definite pockets. Usually protein association occurs between hydrophobic regions called "hot spots", rich in amino acids that are able to form hydrogen bonds and $\pi$-interactions, and only a small number of crucial residues within the complete area are involved in determining binding affinity and specificity. Many hot spots core regions are associated with the presence of $\alpha$-helix, $\beta$-sheet and $\beta$-turn protein secondary structure 
motifs and peptidomimetics targeting PPI have been tailored in the past years to mimic these ordered structures (Robertson and Spring, 2018; Mabonga and Kappo, 2020).

In this scenario, peptides have been discarded as potential lead compounds because they were affected by several issues, namely the random conformations of short sequences, the difficulties in synthesis and purification of longer ones and the sensitivity to endopeptidases, determining generally half-lives of few minutes (Fozgerau and Hoffmann, 2015). Moreover, susceptibility to proteolytic degradation made oral administration a challenge. The development of reliable techniques for peptide synthesis and purification gave access to pharmaceutical grade peptides, even with a high number of amino acids. In addition, molecular design can easily overcome the above-mentioned limits, thanks to the incorporation of non-native amino acids, the introduction of lipophilic side chains or cyclic sequences. For this reason, in the last two decades peptides have found renewed attention (Lau and Dunn, 2018) and up today about 70 therapeutic peptides have been approved and launched on the market. Among the reasons behind the development of new chemical entities (NCEs) in the polypeptide segment there is the commercial and therapeutic success of GLP-1 analogues, Liraglutide and Semaglutide, for the treatment of type 2 diabetes and obesity, that exceeded 7.6 B\$ sales in 2020 (Novo Nordisk 2020 annual report, February 3, 2021). The $13 \mathrm{~h}$ half-life of liraglutide (Neumiller and Campbell, 2009) and the 7 days half-life of semaglutide (Hall et al., 2018), which is also orally available, have been at the basis of the success of these medicines. Several market studies forecasted a consistent global growth and success of the peptide segment, from 29 B\$ sales in 2019 to $48 \mathrm{~B} \$$ in 2025 (excluding insulin), with an annual $10 \%$ increase (Mordor Intelligence, 2020).

We focused this review on the peptides under clinical trials in the last 3 years, that are the direct application of the increased PPI knowledge and of the synthetic design and tactics evolution during the last 10 years. Only therapeutic peptides with a length up to $40 \mathrm{aa}$, according to the FDA definition, are discussed (FDA - U.S. Food and Drug Administration, 2018). We strictly considered therapeutic peptides targeting PPI, excluding diagnostic, radiotherapeutics, vaccines and conjugated peptides with different chemical modalities (Blanco and Gardinier, 2020).

The identification of peptides in clinical phase was not a simple task. The list of peptides under development discussed in this survey is the combination and critical evaluation of information coming from Cortellis-Clarivate, clinical trials databases (United States and Europe) and from companies' web sites, in order to really understand product status. In fact, during the drug discovery and development process few companies communicate NCEs elimination from the pipeline and most of the time the molecule simply disappears from official reports and websites. In addition, the same molecule can be identified with several codes and names due to product sales, codevelopment between companies, company mergers and acquisitions or definition of an international nonproprietary name. The list of discussed molecules includes 58 peptides in different clinical phases: 13 entered the Phase 1, 26 are in Phase 2, 15 are in Phase 3, while four are close to approval being the new drug application (NDA) already submitted to regulatory authorities (Figure 1). A striking difference in respect to the past is the increased number of amino acids, being the number of peptides with 20-40 residues prevailing on shorter peptides (26 vs 21) among the disclosed structures (47 of 58). However, this number should be even higher, considering that nine undisclosed structure are in diabetes and obesity segment, were peptides are typically longer than 20 AA.

With the only exception of two peptides, GT001 and Elsiglutide, that are produced through recombinant technology, all the other compounds with disclosed sequence are synthetically produced, commonly via solid phase approach (SPPS). In this context, many groups worldwide are targeting green innovative techniques (Lawrenson et al., 2017; Ferrazzano et al., 2019; Nuijens et al., 2019; Martin P. et al., 2020). As for the pathologies, diabetes, obesity, cancer and related pathologies are the major areas of interest.

Polypeptides have been classified according to Lau/Dunn definition (Lau and Dunn, 2018): native peptides have the same sequence of endogenous ligand, while analogous are products where the natural sequence has been modified in order to achieve a better pharmacological profile. Heterologous peptides have been discovered independently respect to the natural ligand and are based on a more classical medicinal chemistry approach (Figure 2). It is worth to notice that native peptides and their analogues represent more than $70 \%$ of the PPI targeting peptides in clinical trials, being in particular, the analogue ones accounting for $60 \%$ of the pipeline. The peptides have been discussed on the basis of the target pathology and, besides the clinical trial stage, the route of administration (RoA), as a symptom of peptide pharmacokinetic properties, has been considered (Figure 3).

\section{CANCER AND RELATED PATHOLOGIES}

The role of PPI in the development of tumors is strictly connected to protein-mediated signalling processes, able to activate several biological networks related to tumorigenesis, progression, invasion, and metastasis. For this reason, introducing perturbations in PPI represents an efficient strategy for interrupting cancer-related phenomena. Looking at different tumor phenotypes, specific proteins undergo modifications in their interaction pattern when they become part of carcinogenic phenomenology, with important effects on a patient' state of health. Depending on the tumor localization, it is possible to target different candidate proteins, generally transmembrane receptors or releasing hormone receptors, with theranostic performances useful in understanding cancer progression and improving treatment efficacy (Gulfidan et al., 2020).

Concerning the role of transmembrane receptors in cancer development, Dolcanatide was designed for the treatment of inflammatory bowel disease and functional gastrointestinal disorders to prevent colon cancer. In fact, cells belonging to intestinal epithelium are responsible for controlling toxic pathogens' efflux through the digestive apparatus and transport of nutrients, fluids, and bacterial flora (Rappaport 


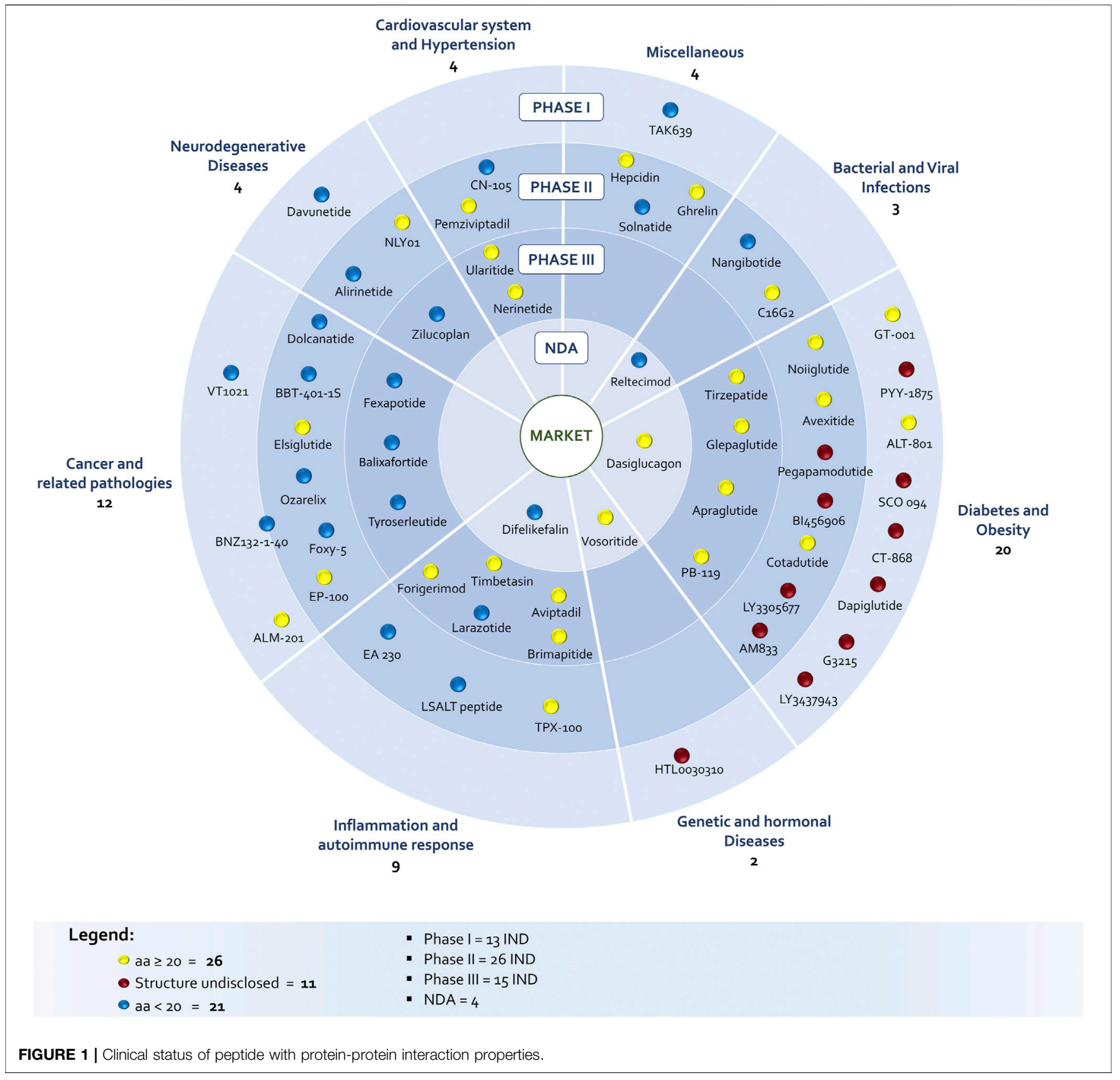

and Waldman, 2018). To maintain homeostatic control of these processes the intestinal epithelial receptor, guanylate cyclase $\mathrm{C}$ (GUCY2C), and its cyclic nucleotide second messenger, cyclic guanosine monophosphate (cGMP), play a critical role. This heterodimeric transmembrane receptor can be activated by endogenous extracellular peptide ligands or other signalling agents, such as $\mathrm{Ca}^{2+}$ and nitric oxide (Boulete et al., 2018). Known ligands for GUCY2C receptor are the bacterial heatstable enterotoxin, ST (cause of traveller's diarrhea), and the endogenous peptides, uroguanylin and guanylin. Dolcanatide was designed to be an analogue of uroguanylin with enhanced resistance to standard digestive breakdown by proteases in the intestine as consequence of the presence of a disulfide bridge. The peptide sequence differs from uroguanylin for the substitution of Asp with Glu at the 3-position at the N-terminus, for greater binding affinity, and for L-Asn1 and L-Leu16 replaced by D-Asn1 and $\mathrm{D}$-Leu16 at the $\mathrm{N}$ - and $\mathrm{C}$-termini, respectively, which are thought to provide enhanced biostability (Shailubhai et al., 2015). Dolcanatide is supposed to bind GUCY2C similarly to uroguanylin and the other known endogenous ligands, via the $\mathrm{NH}_{2}$-terminal $\beta$-hairpin, by providing the third strand of a small triple-stranded antiparallel $\beta$-sheet (Lauber et al., 2003).

Similarly, BBT-401 (structure undisclosed) is an orally available Pellino-1 protein-protein interaction inhibitor for the 


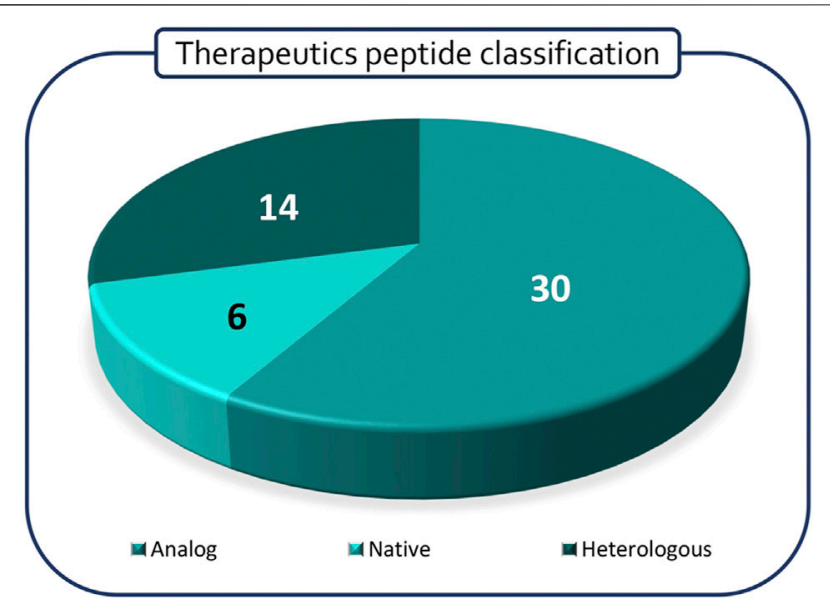

FIGURE 2 | Classification of discussed peptides according to Lau/Dunn classification.

treatment of patients affected by ulcerative colitis. This lipidated tetrapeptide binds Pellino-1 protein, interfering in its signalling cascade. BBT-401 efficiently inhibited the lipopolysaccharideinduced activation of the toll-like receptor proinflammatory signalling pathway, reducing proinflammatory cytokine expression as well. Studies on animal models showed that BBT-401 administration in colitis significantly improved symptoms and histopathological parameters associated to the disorder, and direct colon administration enhances considerably the therapeutic efficacy (Lee et al., 2019).

Interfering on surface receptors functions seems to be particularly relevant for solid and metastatic tumor progression. Foxy-5 is a formylated WNT5A-derived six amino acid peptide, recently used in a Phase 1 trial in patients with metastatic breast, colon and prostate cancer and in a Phase 2 trial for early stage colon cancer. Its model protein, WNT5A, is a member of the Wnt protein family, which plays important roles in several physiological phenomena, like organ development, tissue orientation, cell polarity and migration. Its dysregulation has been associated with progression of various diseases as a consequence of its tumor-suppressive function in colon cancer, neuroblastoma, breast carcinomas, and leukemia (Säfholm et al., 2008; Canesin et al., 2017). In this contest, Foxy-5 has been characterized as a WNT5A-mimicking peptide, since it acts by triggering cytosolic free calcium signalling and by impairing migration and invasion of epithelial cancer cells. In silico prediction suggests that Foxy- 5 could adopt in solution a short loop and alpha helical structure, a motif quite common in protein-protein interactions. In the structure of the full-length native protein, this segment is solvent exposed and could be involved in macromolecular interactions. Foxy- 5 seems to be part of an exosite, expected to be critical for the interactions of WNT$5 \mathrm{~A}$ with receptors and be part of a dimerization site (Figure 4, Villoutreix, 2017).

VT1021 is a cyclic pentapeptide developed by Vigeo Therapeutics whose structure is still undisclosed. It acts as a potent inducer of thrombospondin-1 (Tsp-1) expression in the

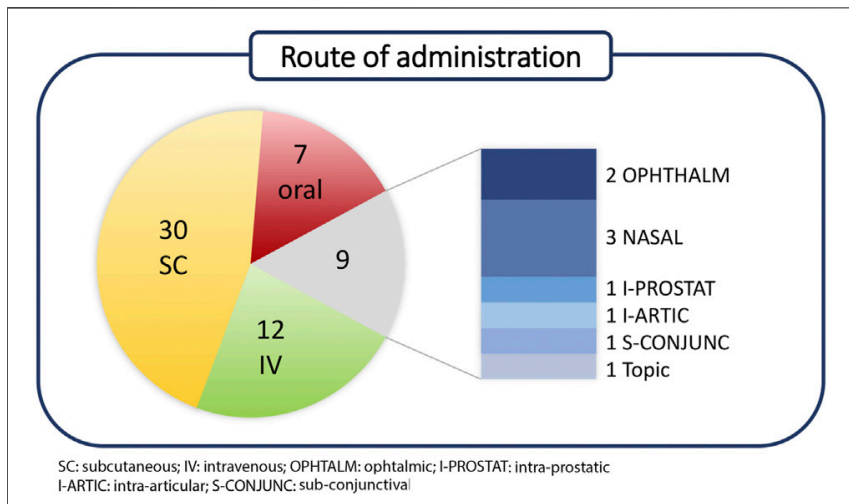

FIGURE 3 | Classification of discussed peptides on the basis of RoA.

tumor microenvironment (TME), which is then totally reprogrammed to reduce its immune-suppressive and tumorpromoting propensity, promoting instead the activation of the adaptive immune system and its tumor-inhibiting inclination (Harb et al., 2019). VT-1021 is at Phase 1 of clinical trials for the treatment of solid tumor since, in preclinical animal models, it showed robust anti-tumor activities on ovarian, pancreatic and breast cancer, with complete tumor regression and reprogramming of the immune TME.

Balixafortide is another good example of a potent and selective antagonist of the chemokine receptor CXCR4, which belongs to the transmembrane receptor family of G-coupled protein receptors (GPCR). This protein is largely expressed in several tumors type, including expression by cells of immune system in carcinogenic tissues. The role of CXCR4 in metastatic phenomena is particularly relevant, since this protein allows cancer cells to migrate to other sites where its natural ligand CXCL12 is expressed, like in the bone marrow of patients affected by breast cancer (Zimmermann et al., 2019). This evidence justifies the application of Balixafortide, in combination with eribulin, in Phase 3 trial for metastatic breast cancer and in a more recent Phase 1 trial for a dose-escalation study (Kaufmann et al., 2020).

In cancer progression and tumorigenesis, interleukin dysregulation has an important role, and its upregulation seems to be associated with many tumors. For this reason, controlling its functions is advantageous for blocking cancer development. BNZ132-1-40 is a 19-mer pegylated peptide belonging to the anticytokine peptide family, active selectively on IL-15, IL-2 and IL-9, which drives T-cell mediated diseases including $\mathrm{T}$-cell large granular lymphocyte leukemia (T-LGLL) and HTLV-1 driven adult T-cell leukemia (ATL) (Massoud et al., 2015; Wang et al., 2019). The peptide structure with helical conformation is responsible for the direct binding to $\gamma \mathrm{c}$ receptor, present in all the above-mentioned cytokines which are fundamental for leukemia survival and lack of strong active therapies. Furthermore, the presence of a PEG-chain was required to increase the peptide half-life. The selectivity of BNZ132-1-40 for Tregs, CD8 ${ }^{+} \mathrm{T}$ and NK cells was confirmed by the absence of adverse effects on other immune cells and the tolerance showed by healthy subjects reported in a recent Phase 1 clinical trial (Nata et al., 2015). 


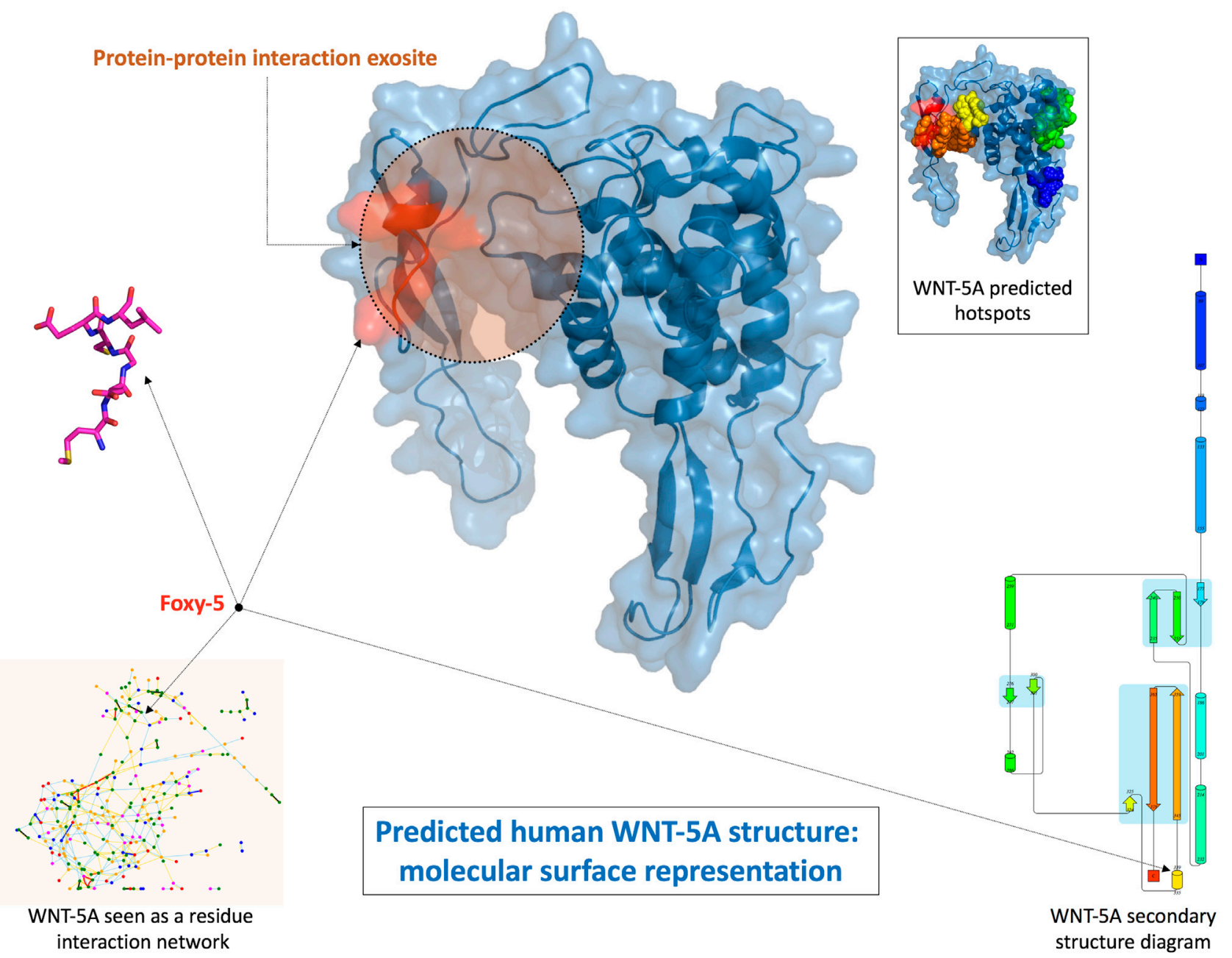

FIGURE 4 | Structural prediction of human WNT-5A and Foxy-5 conformation (Villoutreix, 2017).

ALM-201, that is a 23-mer peptide drug candidate, is a synthetic derivative of $\mathrm{AD}-01$, a 24 -mer peptide containing the sequence $34-58$ of FK506-binding protein like (FKBPL). This protein, that showed prognostic potential in breast cancer, can be classified both as extracellular and intracellular protein: in the first case, it acts as a secreted anti-angiogenic protein targeting cell surface receptor $\mathrm{CD} 44$, upregulated in carcinogenic scenario, while intracellularly FKBPL shows a prognostic activity for breast cancer survival. As a consequence, FKBPL is involved in many cellular processes like cell cycle progression, signalling and differentiation (Annett et al., 2020). ALM201, like other FKBPL derivatives, inhibits breast cancer metastasis through Notch signalling, showing excellent safety profile in Phase 1 clinical trials, when applied for the treatment of ovarian cancer and solid tumor (McClements et al., 2019).

In some cases, the complexity of cancer physiopathology does not allow to clearly identify a single target protein to control cancer progression, even if efficient drug treatments can be applied. As an example, Fexapotide triflutate is a 17-mer peptide in clinical development for prostate cancer and hyperplasia. Even if its mechanism of action remains partially undisclosed, it is known that Fexapotide works stimulating several protein pathways, like caspase, tumor necrosis factor and BCL pathways in prostate glandular epithelial cells. It induces selective cell membrane permeability, mitochondrial metabolic arrest and reduces RNA, DNA lysis and aggregation, with subsequent cell fragmentation and loss, causing decompression of the urethral lumen (Shore et al., 2018). Studies on animal models revealed that Fexapotide direct injection in injured tissues, like bladder, urethra, rectum, periprostatic tissue, leaves unaffected adjacent tissues. For all these evidences, it reached Phase 3 in clinical trials for urinary-related pathologies.

Similarly, Tyroserleutide (YSL) is a tripeptide compound active on primary hepatocellular carcinoma, in Phase 3 of clinical trials. This short peptide, which showed very high activity and few side-effects, was originally purified from the hydrolysates of pig's spleen, but now obtained through chemical synthesis. To carry out its antitumor activity, YSL involves the second messenger $\mathrm{Ca}^{2+}$, which is able to modulate cell function by 
$\mathrm{Ca}^{2+} /$ calmodulin (CaM) pathway. In addition, CaM associates with phosphatidylinositol three kinase (PI3K), enhancing its activity and promoting upregulated cell proliferation (Zhao et al., 2008).

For the treatment of cancer types associated with the functioning of endocrine systems or for controlling side-effects related to other chemotherapeutic treatments, hormone receptors release appears a good targeting strategy to control and stop tumor escalation. Elsiglutide, a selective glucagon-like peptide of type 2 (GLP-2) derivative, was developed as adjuvant to chemotherapy to reduce induced diarrhoea. This new synthetic versions of GLP-2 and elsiglutide show longer half-life, reducing the frequency of administration. (Mayo et al., 2020). The peptide completed successfully a Phase 2 clinical trial.

Ozarelix is a fourth generation Luteinizing HormoneReleasing Hormone (LHRH) antagonist acting on Gonadotropin-releasing hormone $(\mathrm{GnRH})$ receptor, which controls the secretion of luteinizing and follicle-stimulating hormone from the anterior pituitary gland. As other LHRH analogues, it is a 10 -mer peptide with several $\mathrm{D}$-amino acids and bulky residues (in particular in position 6) to enhance stability against proteolysis. Gonadotropin-releasing hormone is a decapeptide (EHWSYGLRPG), displaying an $N$-terminal trimeric fragment responsible for agonist activity and a C-terminal trimer necessary for affinity to the receptor. Since the predominant bioactive conformer consists of a $\beta$-turn, where the two terminals are close together, analogues have been generally designed by replacing the central glycine in position 6 with residues able to stabilize the requested turn (Flanagan and Manilall, 2017). At first, Ozarelix was designed to stimulate secretion of gonadotropins, but continuous evidence demonstrates a decrease of pituitary hormone secretion, as a consequence of gonadotrophic cells desensitization and downregulation of pituitary receptors (Festuccia et al., 2010). In fact, as $\mathrm{GnRH}$ antagonists, Ozarelix induces reduction in gonadotropin levels by inhibition of their secretion from the anterior pituitary gland. Ozarelix completed Phase 2 of clinical trials for the treatment of prostate cancer, showing higher solubility, definitive suppression of testosterone and any risk of clinical flare if compared to other antagonists (Schneider et al., 2010).

EP-100 is a synthetic LHRH natural ligand derivative made up 28 amino acid, 18 of which belong to the cationic a-helical lytic peptide (CLIP-71). Luteinizing-hormone-releasing hormone (LHRH) receptors overexpression has been found in several tumor types, like prostate, breast, ovarian, endometrial, pancreatic, bladder, colorectal, melanoma and non-Hodgkin lymphoma. For this reason, it has been selected as privileged target for treatment of solid and ovarian tumors, where EP-100 is in Phase 1 and 2 of clinical trials, respectively. LHRH sequence (HWSYGLRP) is responsible for the delivery of the lytic peptide to cancer cells via specific binding to the receptor LHRH on cellsurface receptors. The mode of action of EP-100 is not completely known. In fact, the negatively charged outer membrane of cancer cells determines the high selectivity of this peptide for carcinogenic tissues: after binding of LHRH targeting sequence, the positively charged portion of EP-100 interacts with the outer membrane of cancer cells in a disruptive manner, causing cell lysis and death (Curtis et al., 2014; Kim et al., 2020).

\section{INFLAMMATION AND AUTOIMMUNE RESPONSE}

Inflammation and autoimmune responses are essentials body's defence mechanisms. They are the processes by which the immune system recognizes and removes harmful and foreign stimuli and begins the healing processes (Pahwa et al., 2021). However, when an adaptive immune response develops against self-antigens or there is an upregulated recruitment of proinflammatory molecules, it is usually impossible for immune effector mechanisms to completely eliminate the antigen/proinflammatory molecules, and therefore a sustained response occurs (Janeway et al., 2001). In this perspective, peptidebased treatments able to interfere with the dysregulated body's defence were developed.

Forigerimod (ImmuPharma, 2019) is a synthetic 21-mer linear peptide, phosphorylated in correspondence of Ser11 position, produced by ImmuPharma and designed from the small nuclear ribonucleoprotein U1-70 (Zimmer et al., 2013). As suggested by its commercial name, Lupuzor ${ }^{\mathrm{TM}}$ is employed for the treatment of Systemic Lupus Erythematosus (SLE), a chronic, life-threatening autoimmune, inflammatory disease affecting multiple organs such as skin, joints, kidneys, blood cells, brain, heart and lungs. Due to the high relevance of this pathology, Lupuzor $^{\mathrm{TM}}$ received fast-track designation from the FDA, which expedites the drug's approval process (ImmuPharma, 2021). Currently, the mechanism of action of Lupuzor ${ }^{\mathrm{TM}}$ has not been fully elucidated; however, several studies have shown that it displays tolerogenic and immunomodulatory effects leading to the inhibition of $\mathrm{T}$ cells' reactivity in presence of endogenous peptides.

On the other hand, for the treatment of Systemic Inflammatory Response Syndrome (SIRS) the intravenous infusion of EA-230, a synthetic 4-mer linear peptide produced by Exponential Biotherapies, is currently under investigation (Phase 2). The sequence was designed on the basis of the $\beta$-loop contained in the $\beta$ subunit of the endogenous peptide human Chorionic Gonadotropin (hCG) (van den Berg et al., 2011). The SIRS pathology is caused by an upstream of proinflammatory agents (such as IL-6) and this dysregulated inflammatory response often results in tissue damage, failure of one or more organ systems, and high mortality. Even though the mechanism of action EA-230 is still unclear, biological evidence have demonstrated how changes of the hormonal milieu play a central role in the anti-inflammatory response (van Groenendael et al., 2019).

Another peptide employed to cure inflammation diseases is Difelikefalin acetate, a synthetic 5-mer linear D-peptide produced by Cara Therapeutics and designed starting from the sequence of the endogenous peptide Dinorphin A. As such, Difelikefalin acetate is an agonist of $\kappa$-opioid receptor (KOR) for the treatment of Chronic kidney disease-associated pruritus (CKD-aP), or uremic pruritus, and it has completed Phase 3 
clinical trials in 2020 (Fishbane et al., 2020). CKD-aP is a severely distressing condition that occurs in more than $60 \%$ of patients undergoing dialysis and, even if the pathogenesis is still incompletely understood, opioid imbalance has been identified as a possible reason of the arise of this pathology (Lipman and Yosipovitch, 2020). Due to the ubiquitous nature of KOR (in peripheral and central nervous system), Difelikefalin acetate was designed as a selective agonist, avoiding the penetration into the CNS that aims to provide the benefits of minimizing itch through activation of the anti-pruritic KOR system without causing CNS side effects.

Moving to inflammation affecting the respiratory system, it is possible to mention the LSALT peptide, a synthetic 16-mer linear peptide developed by Arch Biopartners and still ongoing in Phase 2 clinical trials (Arch Biopartners, 2021) for the treatment of Acute Respiratory Distress Syndrome (ARDS). A hallmark feature of this inflammation is the recruitment of neutrophils from the bloodstream into inflamed tissue (Choudhury et al., 2019). In this context, dipeptidase-1 DPEP1, an anchored membrane protein, has been identified as the major adhesion receptor on the lung and liver endothelium for neutrophil sequestration, independently from its enzymatic activity. As a consequence, the inappropriate recruitment of neutrophils to various organs contributes to multi-organ dysfunction (such as pulmonary dysfunction). In order to prevent this healthy disfunctions, several experimental models have highlighted that LSALT peptide binds to DPEP-1 not inhibiting its enzymatic activity but preventing the neutrophils sequestration and the inflammation response.

Remaining within the ARDS treatment, Avipdtadil is a synthetic 28-mer linear peptide developed by NeuroRX and Relief Therapeutics Holding, designed starting from endogenous Vasoactive Intestinal Peptide (VIP) structure. This endogenous protein is involved in the development of pulmonary hypertension ( $\mathrm{PH}$ ), a progressive vascular disease caused by vasoconstriction and structural remodeling of arterioles, leading to dyspnea, fatigue, cough, chest pain, palpitations, peripheral edema, syncope, right heart failure, and death. Moreover, without treatment, $\mathrm{PH}$ can evolve in ARDS halving the survival rate within 5 years (Hu et al., 2015). As VIP analogue, Aviptadil through binding to G-protein coupled receptors (VPAC1, VPAC2 and PAC1) induces pulmonary vasodilation and shows anti-inflammatory properties. In fact, Aviptadil aerosol is still ongoing in Phase 2/3 for the treatment of ARDS leading to a small and temporary but significant selective pulmonary vasodilation, an to an improved stroke volume and mixed venous oxygen saturation (Leuchte et al., 2008).

Larazotide, a $9 \mathrm{~m}$ Biopharma's investigation drug (9 Meters Biopharma Inc., 2021), is the only therapeutic candidate for celiac disease adjuvant therapy, advanced to a Phase 3 clinical trial, that minimizes symptoms in tandem with gluten free diet. This octapeptide derives from the Zonula Occludens toxin secreted by Vibrio cholerae and it is an antagonist of zonulin, the only known physiological modulator of the intercellular tight junctions and a key player in regulation of the mucosal immune response in small intestine (Heickman et al., 2020).

Moving to more specific areas of the body, the treatment of the hearing and ocular inflammations is particularly interesting.
Brimapitide is a synthetic dextrogyre 31-mer linear peptide developed by Auris Medical and designed from a combination of a 20 -mer sequence of protein islet-brain 1 (IB-1) and 10-mer trans-activator of transcription sequence (TAT) of the HIVTAT protein, which allows its intracellular penetration. Its similarity with IB-1 makes this peptide a selective inhibitor of c-Jun $\mathrm{N}$-terminal Kinase (JNK), a ubiquitous intracellular enzyme. (Chiquet et al., 2017). Its inhibition prevents formation of transcription complexes and further progress along the apoptotic pathway or activation of genes, which are encoding inflammatory molecules (such as cytokines). For this reason, Brimapitide is under investigation (Phase 3 clinical trials) for the treatment of acute sensorineural hearing loss (ASNHL) and ocular inflammation as biocompatible intratympanic hyaluronic acid gel and ophthalmic solution, respectively (Suckfuell et al., 2014).

Regarding the treatment of ocular inflammation, it is worth to mention Timbetasin, a synthetic 43-mer linear peptide produced by RegeneRX Biopharmaceuticals which behaves as analogue of the endogenous peptide Thymosin $\beta 4$ from which it differs in the $\mathrm{N}$-terminus acetylation. As such, Timbetasin is involved in the treatment of moderate to severe dry eye disease, thanks to its antiinflammatory effect. Dry eye is a chronic ocular surface disease, causing visual morbidity that affects the quality of life, and it's associated with an increase in the levels of inflammatory cytokines in both the conjunctiva and tears (Sosne et al., 2015). Generally, endogenous Thymosin $\beta 4$ promotes wound repair and regeneration in the skin, eye, heart, and nervous system in various animal models; moreover, it is known to modulate the expression of multiple signalling molecules, playing a role in the downregulation of transcription factors for inflammatory chemokines, cytokines, and metalloproteinases (Sosne and Ousler, 2015). For this reason, the topical supplementary administration as eye drop solution of Timbetasin is currently under investigation (Phase 3 clinical trials) for the promotion ocular surface healing, increase corneal epithelial cell migration, and decrease corneal proinflammatory cytokine levels.

Finally, for the treatment of inflammation of bone tissue, TPX-100, a synthetic 23-mer peptide which structure is currently undisclosed, is under investigation (OrthoTrophix, 2021). This peptide is produced by OrthoTrophix and designed starting from Matrix Extracellular Phosphoglycoprotein (MEPE), a protein belonging to the family of Small Integrin-Binding Ligand N-linked Glycoproteins (SIBLING) (McGuire et al., 2018). Evidence shows that these proteins play key roles in the mineralization of bones and dentin without a clear knowledge of the mechanism of action. It has been shown that the bone shape of the knee undergoes unidirectional and irreversible change over time, with a much greater rate of change in osteoarthritic knees than in normal ones (OrthoTrophix, 2021). Such accelerated bone shape mutation starts much earlier than cartilage degeneration and appears to be the most reliable structural marker, to date, for onset of osteoarthritis (OA). Even if the mechanism of action is still undisclosed, TPX-100 has completed Phase 2 clinical trial for the treatment of the knee osteoarthritis, inducing the 
regeneration of normal tibiofemoral hyaline cartilage and highlighting a statistically significant correlation between stabilization of tibiofemoral cartilage and critical knee functions.

\section{GENETIC AND HORMONAL DISEASES}

Genetic disorders can be caused by a mutation in one gene (monogenic disorder), by mutations in multiple genes (multifactorial inheritance disorder), by a combination of gene mutations and environmental factors, or by damage to chromosomes (National Human Genome Research Institute NHGRI, 2021). On the other hand, hormonal disorders may result from a problem in the glands themself, or because the hypothalamic-pituitary axis (interplay of hormonal signals between the hypothalamus and the pituitary gland) provides too much or too little stimulations (Emanuele and Emanuele, 1997). In this context, peptide-based treatments can be employed both as complementary supply of the lacking endogenous molecules (genetic disorders) or/and as interfering agents on the mechanisms responsible for their dysregulated production (hormonal disorders).

HTL0030310 is a new synthetic peptide produced by Sosei Heptares which has recently completed Phase 1 of clinical trials for the evaluation of its safety and tolerability towards healthy subjects. Even though HTL0030310 structure is still undisclosed, Sosei Heptares designed this peptide as a selective SSTR5 (somatostatin 5) receptor agonist to treat endocrine disorders (Sosei Heptares, 2019) modulating the excess release of hormones from adenomas (benign tumors) of the pituitary gland. Highly elevated plasma levels of pituitary hormones result in a number of serious disorders including Cushing's Disease, a debilitating endocrine disorder caused by the overproduction of the hormone cortisol.

On the other hand, Vosoritide is a synthetic 39-mer cyclic peptide produced by BioMarin Pharmaceutical and currently in Phase 3 of clinical trials for the treatment of achondroplasia, the most common form of disproportionate short stature in humans (Savarirayan et al., 2020). This condition is caused by an autosomal dominant mutation in the fibroblast growth factor receptor 3 (FGFR3), a gene that constitutively activates the mitogenactivated protein kinase (MAPK), which inhibits endochondral ossification (Savarirayan et al., 2019). Since C-type natriuretic peptide (CNP) and its receptor, natriuretic peptide receptor 2 (NPR2), are potent stimulators of endochondral ossification, it was observed that a continuous intravenous infusion of exogenous C-type natriuretic peptide restores the impaired bone growth. Vosoritide was designed as a cyclic analogue of C-type natriuretic peptide in order to increase the half-life in comparison with its endogenous form.

\section{DIABETES, OBESITY, SHORT BOWEL SYNDROME AND HYPERINSULINEMIA, THE PROGLUCAGON LEGACY}

Over the last decades, a series of synthetic peptides derived from the gut endocrine system were identified as promising treatments for metabolic diseases such as Type 2 Diabetes Mellitus (T2DM) and obesity. These pathologies still remain global health problems in continuous increase, known to reduce quality of life and to lead to serious complications (Bastin and Andreeli, 2019). The therapy of T2DM involves agents targeting body weight and simultaneously maintaining blood glucose control.

The main synthetic therapeutic peptides have been designed by mimicking the sequences deriving from the pro-hormone proglucagon metabolic cleavage. This 158 -mer small protein is submitted in pancreas, gut and central nervous system to specific posttranslational processing by prohormone convertase enzymes, leading to the generation of shorter fragments (Figure 5). Among them, glicentin-related pancreatic peptide (GRPP), glucagon, intervening peptide-1 (IP-1) and intervening peptide-2(IP-2), major proglucagon fragment (MPGF), oxyntomodulin (OXM), glucagon-like peptide-1 (GLP-1) and glucagon-like peptide-2 (GLP-2) have a prominent role in glucose control, energy balance and gut homeostasis and were hence proposed as models for drug design (Lafferty et al., 2021).

\section{Glucagon Like Peptide-1 Receptor Targeting Peptides}

One of the main biological targets for pharmaceutical action is the Glucagon like peptide-1 receptor (GLP-1R), a class BGprotein coupled receptor (GPCR), which is deeply involved in insulin secretion and homeostasis. Like other G-proteins, the GLP-1R is characterized by the seven transmembrane a-helices separated by three intracellular and three extracellular loops.

The GLP-1R activation is related to the secretion of glucagon like peptide 1 (GLP-1), an incretin glucoregulatory peptide released in the gut after food intakes. GLP-1 exists in two forms: GLP-1(7-37) and GLP-1(7-36) amide, with the latter being more abundant in circulation after eating. These peptides, interacting with GLP-1R, enhance the insulin secretion and normalize the glucose levels through the receptor signalling, via cyclic adenosine monophosphate (cAMP) production (Druker and Nauck, 2006). When the regulatory effect is complete, the GLP-1 is inactivated by proteolysis. Over this main effect, GLP-1 and its agonists can reduce the glucagon secretion, slow the gastric transit and decrease the energy consumption extending the effects on treatment of obesity. The key role of the GLP-1R/GLP-1 system is reflected by the efforts recently made in developing efficient GLP-1R peptide agonists for pharmacological treatment of T2DM (Sloop et al., 2018).

A great advance in the field was reached with the discovery of exendin-4 in the venom of the Gila monster lizard. Exendin-4 (or Exenatide, as it has been called its synthetic form) is a 39 -mer peptide resistant to dipeptidyl peptidase 4 (DPP-4), which shows a better pharmacokinetic than GLP-1 thanks to a Gly ${ }^{2}$ residue in its sequence. Exenatide was approved by FDA in 2005 and is dosed as a twice daily injection (Donnelly, 2012). Currently the best in class drugs for T2DM and obesity are liraglutide and more 


\section{Proglucagon}

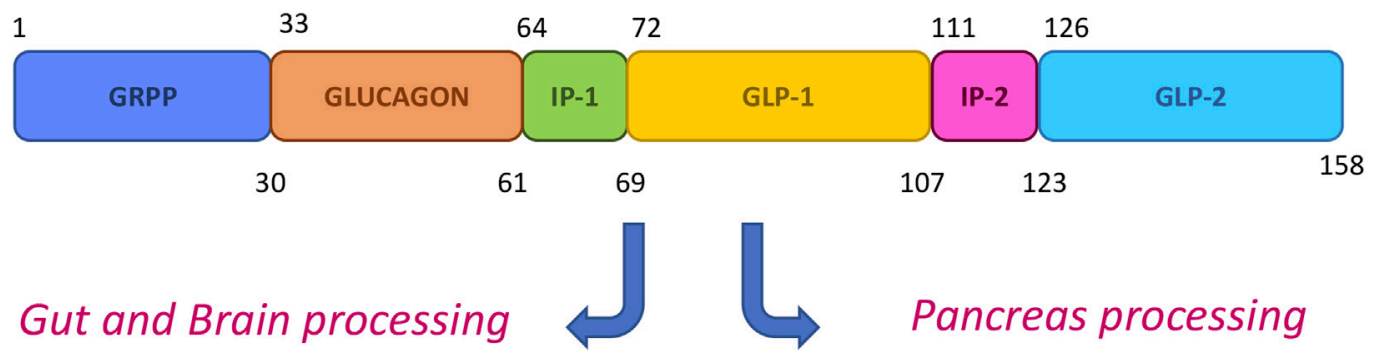

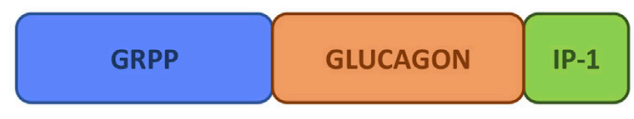

Glicentin

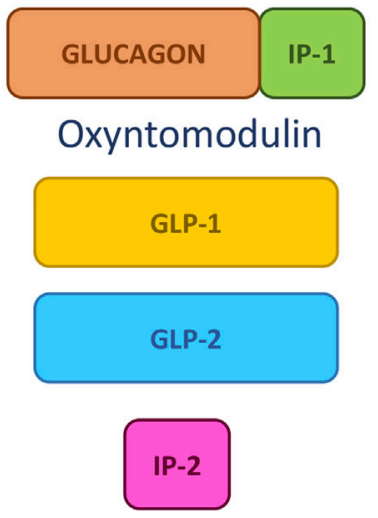

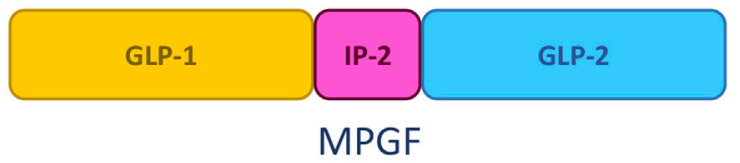
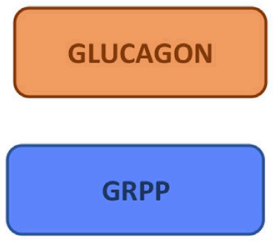

IP-1

FIGURE 5 | Tissue-specific proglucagon cleavage.

recently the orally disposable semaglutide. These two molecules foster the research for better GLP-1 analogues with improved pharmacological profile.

Following these therapeutic needs, further modifications of the exenatide sequence led to slow-release compounds: an example is PB-119, a polyethylene glycosylated exenatide developed by PegBio and obtained by modification of a single amino acid in exenatide, replacing $\mathrm{Ser}^{39}$ with Cys (Min Xu et al., 2019). Even if the mechanism of action is identical to that of Exenatide, the PEGylation on the analogue $\mathrm{PB}-119$ reduces the excretion rate in the kidneys, and its increased molecular weight causes steric hindrance toward DPP-4, prolonging the half-life and allowing one weekly subcutaneous injection dose regimen (Cui et al., 2020). The same concept of improved pharmacokinetic and resistance to DPP-4 was declined also by Jiangsu Hansoh Pharmaceutical through the development of the GLP-1R agonist Noiiglutide, a 40-mer exenatide analogue, currently in Phase 2 trials as subcutaneous injectable agent. Structurally, the presence of an unnatural Aib ( $\alpha$-amino isobutyric acid) residue in position two should guarantee a better resistance toward enzymatic hydrolysis while the condensation with palmitic acid on $\mathrm{Lys}^{1}-\xi-\mathrm{NH}_{2}$ enhances the hydrophilicity (Wang et al., 2012).

The GLP-1R agonist roster includes also G3215 (structure undisclosed), developed by Imperial College, that completed its Phase 1 trials in 2019 (Serrano et al., 2017).

As above described, GLP-1R agonist peptides are receiving an increasing interest, with several agents advancing the clinical phases. In comparison, less efforts have been focused on studying GLP-1R antagonists. Nevertheless, Eiger BioPharmaceuticals is developing Avexitide for treating post-bariatric hypoglycemia $(\mathrm{PBH})$, a form of hyperinsulinemic hypoglycemia $(\mathrm{HH})$, as a new liquid formulation of Exendin 9-39 intended for subcutaneous injection administration. $\mathrm{PBH}$ is a rare disease without approved pharmacotherapy, caused by abnormal growth in insulin secretion, which is attributed to exaggerated postprandial secretion and to the large increase in meal induced GLP-1 release (Craig, 2020). Therefore, GLP-1R antagonism could represent a potential therapeutic strategy for managing this condition. Avexitide is a 31-mer peptide that selectively targets and blocks GLP-1R, normalizing insulin secretion and thus decreasing postprandial hypoglycemia. Data released from a 
recent Phase 2 clinical trial showed that Avexitide produced consistent improvements in the incidence of hypoglycemia maintaining a good tolerability profile (Suzuki et al., 2020).

\section{Glucagon Like Peptide-1 Receptor/GPCR Glucagon Receptor Targeting Peptides}

The clinical success of GLP-1R agonist peptides has prompted the search for agents that could combine the benefits of GLP-1 with those of other key gut hormones, in order to target multiple signalling pathways with a single molecular entity. Moreover, this emerging dual pharmacological approach may lead to increased metabolic action compared to monotherapies, and a number of these candidates are being evaluated in clinical trials (Bastin et al., 2019).

Glucose homeostasis is regulated by the combinatorial action of insulin and glucagon. While insulin and its therapeutic applications were widely studied, the glucagon hormone, secreted by the pancreatic a-cells, has been receiving attention only in the last decades. Its main action consists in a counterregulatory effect toward insulin, inducing hepatic glycogenolysis and gluconeogenesis by targeting the class B GPCR glucagon receptor (GCGR) (Herr, 2012). The use of native glucagon in the therapeutic approach to hypoglycaemia is not easily practicable (Patil et al., 2020) for its very low stability in physiological formulations and its consequent high tendency to aggregate in few hours, after reconstitution (Hövelmann et al., 2018). Thus, the development of new analogues/agonists of the native glucagon peptide is necessary in treatment of hypoglycaemia. Zealand Pharma developed, Dasiglucagon (NDA) which will be launched on the market in the first trimester of 2021 as Zegalogue ${ }^{\circledR}$, a ready-to-use formulation administered by singleinjection pen applicator. To avoid aggregation problems and fibril formations and to render it physically and chemically stable in aqueous solution, Dasiglucagon was designed introducing seven substitutions in the 29 amino acid sequence of the native glucagon, with the insertion of an Aib residue (Pieber et al., 2020).

On the other hand, glucagon enhances energy consumption and acts as food intake regulator, making its analogues also interesting for glucose regulation in T2DM and obesity (Suzuki et al., 2020). GLP-1 and glucagon have a high sequence homology: this aspect encouraged the development of multiple molecules with an integrate pharmacological profile targeting both GLP-1R and GCGR in a dual-agonism mechanism, where glycaemia and weight control are accompanied by adipose tissue lipolysis and appetite suppression (Capozzi et al., 2018). The native gut hormone peptide Oxyntomodulin (OXM), secreted after food ingestion, exhibits an antidiabetic effect and drives weight loss acting on appetite and satiety by activating both GLP-1R and GCGR, even if showing lower activity compared to GLP-1 and glucagon alone. Thus, oxyntomodulin has been chosen as a model for the development of GLP-1R/GCGR dual agonists.

Within this class, Pegapamodutide (OPK880033), by OPKO Health, completed phase 2 for once-weekly administration in treatment of T2DM. This drug candidate consists in a PEGylated analogue of OXM and displays a long action since the presence of two PEG moieties on $\mathrm{Cys}^{38}$ and $\mathrm{Cys}^{39}$ prevents enzymatic degradation (Sheetz et al., 2017) The resistance toward DPP-4 is also provided by the presence of two un-natural Aib residues along the sequence. In particular, $\mathrm{Aib}^{2}$ enhances potency and selectivity at the GLP1-R. (Connop et al., 2020).

In addition, MedImmune, a subsidiary of AstraZeneca, is developing Cotadutide (MEDI0382), presently in Phase 2 as once-daily, subcutaneous therapy, to treat overweight or obese patients with T2DM. This novel dual GLP-1R/GCGR agonist was designed to improve glycaemic control and to facilitate weight loss through combined effects on appetite and energy expenditure (Ambery et al., 2018). Structurally, MEDI0382 is a 30 -mer synthetic linear peptide, designed as OXM analogue, wherein the sequence of oxyntomodulin has been C-terminally depleted of seven residues, while seven of the remaining amino acids have been changed. Its extended half-life was achieved by enhancing stability to peptidase degradation: $\mathrm{Gln}^{20}$ and $\mathrm{Gln}^{24}$ were replaced with residues not susceptible to deamidation, whilst $\mathrm{Arg}^{17}$ was substituted with Glu to decrease proteolysis. Moreover, the insertion of a palmitic acid side chain at Lys ${ }^{10}$ through a $\gamma$-glutamate moiety promoted its reversible binding to albumin (Henderson et al., 2016). In such a way, this degradation resistant peptide is able to exert an optimally balanced dual agonism, inducing in clinical trials' patients an observed weight loss greater than that observed with GLP-1R alone.

Another long-acting GLP-1R/GCGR dual agonist, BI456906, is being developed by Zealand Pharma in collaboration with Boehringer Ingelheim. This peptide is an analogue of the natural OXM and is being investigated in Phase 2 for T2DM and obesity, (Zealand Pharma, 2020). Efficacy of BI456906 as a treatment for non-alcoholic steatohepatitis (NASH), the most severe form of non-alcoholic fatty liver disease (NAFLD), is also expected, due to the emerging successful approach for this pathology using dual GLP-1R/GCGR agonists.

In this field, ALT-801 emerged as a novel peptide-based dual GLP-1R/GCGR agonist designed by AltImmune to treat the obesity and metabolic dysfunction caused by NASH. As observed in a preclinical model of the disease, ALT-801 induced significant weight loss compared to semaglutide, and accordingly the company recently announced the beginning of a Phase 1 clinical trial.

Its structure is based on a 29-mer sequence partially mimicking both GLP-1 for an improved weight loss and glucagon for restoring metabolic functions (Nestor et al., 2021). The insertion of an Aib residue was meant to prevent the proteolytic degradation, while a EuPort ${ }^{\mathrm{TM}}$ liposaccharide surfactant, formed by a D-glucoside linked to a methylene C18 chain, was introduced on Lys $^{17}$ side chain to improve gastrointestinal tolerability. In addition, $\mathrm{Glu}^{16}$ and $\mathrm{Lys}^{20}$ side chains were conjugated to create a lactam ring, designed as a helix stabilizer to increase potency. These structural features afforded a high serum albumin binding, leading to a suitable once-weekly subcutaneous administration in patients (AltImmune, 2019). Finally, LY3305677 (OXM3, IBI362) is an undisclosed peptide dual GLP-1R/GCGR agonist, reported by Ely Lilly as a thirdgeneration analogue of Oxyntomodulin, that is currently under evaluation in Phase 2 clinical trials. 


\section{Glucagon Like Peptide-1 Receptor/GIPR Targeting Peptides}

Another strategy to treat diabetes and obesity with dual active peptides is exploiting the agonism toward incretin receptors GLP$1 \mathrm{R}$ and GIPR. GIPR is the natural target of the native gut hormone glucose-dependent insulinotropic polypeptide (GIP), secreted by the $K$-cells after food intakes. This incretin peptide can stimulate insulin and glucagon secretion, like GLP-1, but with a weaker efficacy on the regulation of the insulinotropic effect. Studies on the receptor-ligand interaction pointed out the key role of the native peptide N-terminus in GIPR activation. This moiety interacts with a binding pocket in the transmembrane receptor, while the central residues bind to the extracellular domain of the receptor. Accordingly, a tuning of the $\mathrm{N}$-terminal moiety could modulate the agonism or the antagonism of the peptide (Gasbjerg et al., 2018).

Therefore, the GIP agonism has been identified as a pharmaceutical strategy for the treatment of T2DM, even if it seems to be less relevant than GLP-1 agonism. Synthetic dual incretin receptor agonists, nicknamed "twincretins," have been investigated in the last years, with a few candidates actually in clinical development. The most advanced GLP-1R/GIPR agonist is Tirzepatide (LY3298176) from Eli Lilly, currently in Phase 3 trials. Tirzepatide is formulated as a synthetic 39-mer linear peptide, sharing 19 residues with native GIP. The peptide sequence incorporates the amidated C-terminus and two nonnatural Aib residues at positions 2 and 13. Moreover, the structure is conjugated to a 20 -carbon fatty diacid moiety via a hydrophilic linker connected to the $\mathrm{Lys}^{20}$ residue. This strategy was designed to promote albumin binding, prolonging Tirzepatide half-life to approximately 5 days and thus enabling once-weekly subcutaneous dosing regimen (Coskun et al., 2018). In phase 1 and 2 clinical trials, Tirzepatide produced significantly improved clinical efficacy, safety and tolerability in glucose control and weight loss compared with the GLP-1 agonist dulaglutide. GIPR binding affinity resulted comparable to that of native GIP, while a GLP$1 \mathrm{R}$ affinity five times lower than that of native GLP-1 was observed (Min and Bain, 2021).

It is worth mention that also the dual agonist peptide SCO094, developed by Scohia Pharma in partnership with Takeda Pharmaceuticals (Clemmensen et al., 2019) belongs to this class of drug candidates. This molecule is being tested in both longacting and oral formulations in Phase 1 with wide potential applications comprising diabetes, obesity and NASH.

Finally, the dual agonist CT-868, developed by Carmot Therapeutics, will enter in Phase 2 in the first half of 2021 as a promising treatment for diabetes, obesity and NASH (Kim and Kim, 2020). CT-868 dual agonist candidate was discovered using the Chemotype Evolution technology, as a peptide-small molecule hybrid compound, able to mimic the native GLP-1 hormone (Carmot Therapeutics Pipeline, 2021).

On the basis of the promising results of dual targeting peptides, some ternary agonists concurrently targeting GLP-1, GCGR and GIPR have been developed. The peptide LY3437943 from Ely Lilly is the first member of this novel class of peptides, designed to be effective in T2DM and obesity treatment. The structure of this peptide is still undisclosed by the originator.

\section{Y Receptor Type 2 Targeting Peptides}

Other potential therapies for obesity and associate pathologies involve PYY and amylin agonists.

Peptide YY (PYY) is a gut hormone that is co-secreted from the entero-endocrine L cells, together with GLP-1 and oxyntomodulin, in response to feeding (Khoo and Tan, 2020). Although it exists in two major forms, the full length PYY1-36 and PYY3-36, the latest is the most commonly biologically active circulating form. PYY3-36 is a 34-mer peptide released postprandially by the gut. Its secretion activates appetite suppression and food intake decrease by acting, in the arcuate nucleus of the hypothalamus, on neuropeptide $\mathrm{Y}$ receptor type 2 (Y2R), a member of the neuropeptide $\mathrm{Y}$ receptor family that belongs to the GPCR family (Srivastava and Apovian, 2018).

Early clinical studies showed that PYY3-36 infusion in obese patients induced suppression of food intake with good tolerability, and limited side effects. Anyway, since native PYY short half-life ( $8 \mathrm{~min}$ ) affects clinical stability, various approaches have been planned to increase its resistance to proteolytic inactivation (Will et al., 2017). In this context, alternative delivery of PYY is a challenge. Recently, Gila Therapeutics has developed GT-001, a PYY3-36 analogue that started Phase 1 trials with orally available sublingual formulation (Acosta et al., 2019). Novo Nordisk's pipeline also includes a novel analogue of the appetite-regulating hormone PYY, namely PYY-1875, whose structure is still undisclosed. This peptide is currently in Phase 1 and is intended as subcutaneous injection for once-weekly treatment (Novo Nordisk, 2020).

Amylin is a 37-mer peptide hormone mainly produced in the pancreatic beta cells and co-secreted with insulin during a meal. Amylin has a well-established role as a satiety signal; it acts by reducing food intake and postprandial glucagon secretion via binding to human amylin receptors (AMY) in specific areas of the brain (Zakariassen et al., 2020). AMY subtypes are GPCR consisting of a calcitonin receptor (CTR) and one of three receptor activity-modifying proteins (RAMP). Because of their mechanism of action, amylin mimetics are novel targets of study as anti-obesity drugs and several approaches (PEGylation, glycosylation or albumin binding) have been explored to extend their half-life and reduce their administration frequency. Novo Nordisk is currently testing AM833 in phase 2 trial, a long-acting acylated analogue of the human amylin hormone, in once-weekly subcutaneous administration, AM833 has been evaluated in combination with the GLP-1 analogue semaglutide in a phase 1 clinical trial (Mathiesen et al., 2020).

\section{Glucagon-Like Peptide-2 Receptor Targeting Peptides}

Glucagon-like peptide-2 receptor (GLP-2R) is a GPCR superfamily member expressed in the gastrointestinal tract and, belonging to the family of seven trans-membrane receptors, it is closely related to GCGR and GLP-1R. Through binding to glucagon-like peptide-2 (GLP-2), GLP-2R directly 
inhibits apoptosis and increases intestinal growth by stimulating cell proliferation in response to ligand activation. GLP-2 is a 33mer hormone released by the enteroendocrine intestinal L-cells in response to nutrient ingestion (Brubaker, 2018).

Although the mechanisms by which GLP-2 mediates its effects still remain not completely understood, it is an important regulator for stimulating intestinal growth, increasing absorption, promoting healing and maintaining epithelial integrity, in both normal humans and patients with intestinal failure consequent to massive intestinal resection (short bowel syndrome, SBS). Indeed, patients with SBS might have impaired postprandial GLP-2 secretion, which is instead required for optimal intestinal adaptation. The use of GLP-2 as a therapeutic agent is limited because of its very short circulating half-life (approximately $7 \mathrm{~min}$ ) due to cleavage by DPP-4 (Hargrove et al., 2020). Consequently, pharmacologically active GLP-2 analogues with a longer half-life and reduced clearance are under development against SBS, including phase 3 agents Apraglutide (VectivBio) and Glepaglutide (Zealand Pharma).

Glepaglutide is a highly potent GLP-2R selective 39-mer peptide, with a long-acting effect and an effective plasma halflife of approximately $50 \mathrm{~h}$, allowing a less-than-once daily administration. Furthermore, it offers a more convenient dosing form via a ready-to-use autoinjector device, which removes the requirement for reconstitution from lyophilized powder and allows the formation of a subcutaneous depot at the site of the injection, from which it could be slowly released into the circulation (Naimi et al., 2019). Glepaglutide differs from native GLP-2 through the insertion of a C-terminal tail consisting of six lysine residues that modify the charge state aiding solubility and physicochemical properties. The $\mathrm{N}$-terminal region was optimized by changing five amino acids for improving pharmacokinetic and potency properties, and by replacing other four residues with alanine in an internal region, ending in a globally nine amino acid substitution.

Apraglutide is another highly selective, potent GLP-2R agonist peptide, composed by a 33 amino acid sequence, with a molecular structure designed to preserve optimal pharmacological activity while increasing the half-life compared to native GLP-2 or other GLP-2 analogues (Martchenko et al., 2020). Specifically, native GLP-2 was modified at positions 2, 10, 11 and 16 with Gly, Nle, D-Phe and Leu respectively, and with a C-terminal amidation. The few amino acid substitutions translate into a superior pharmacokinetic profile that results in an exceptionally low clearance and in a high plasma protein binding, thus enabling a long in vivo elimination half-life after subcutaneous administration $(30 \mathrm{~h})$, without necessity of conjugation or other peptide modifications. Moreover, Apraglutide displays a good stability against DPP-4, allowing the possibility for only once-to-twice weekly treatment (Slim et al., 2019).

The effect of the native GLP peptides was investigated in SBS patients either as a selective agonist (GLP-1R or GLP-2R) or as a dual GLP agonist combination therapy, with the latter imparting superior efficacy and better patient outcomes compared to each single agent alone (Suzuki et al., 2020). This rationale supported the use of dual GLP receptor co-agonism for the treatment of metabolic and gastrointestinal diseases, even if clinical studies are still awaiting to confirm the therapeutic efficacy of its combination. Following this approach, Zealand Pharma is currently developing Dapiglutide, previously referred to as ZP7570. Even if its structure is still undisclosed, the company announced that this molecule completed Phase 1 trials in 2020 and showed a good safety and tolerability profile in healthy volunteers together with a plasma half-life allowing for onceweekly dosing (Zealand Pharma, 2020).

\section{CARDIOVASCULAR SYSTEM AND HYPERTENSION}

Cardiovascular diseases (CVD) are among the leading causes of death worldwide, taking an estimated 17.9 million lives each year. According to the World Health Organization (WHO), four out of five CVD deaths are due to heart attacks and strokes, and one third of these deaths occurs prematurely in people under 7 years of age (WHO, 2021). In the last years, proteins and peptides with unique biological activity and metabolism have successfully caught the attention of researchers as an alternative treatment for cardiovascular and hypertension diseases and several are still under clinical study waiting to be approved.

Ularitide, an atrial peptide agonist, was developed by Cardiorentis, a private biopharmaceutical company, specialized in the treatment of cardiovascular diseases, as an intravenous treatment for acute heart and kidney failure, and has completed the Phase 3 in 2018 (Emani et al., 2015). Ularitide is the chemically synthesized form of urodilatin, a human endogenous natriuretic peptide produced in the kidneys with the aim to regulate fluid balance and sodium homeostasis. This 32-mer-containing peptide has the same sequence of the 28 amino acid-containing atrial natriuretic peptide (ANP), except for the addition of four amino acids at the $\mathrm{N}$-terminal extension. The crystal structure of ANP bound to the receptor showed that the complex contains two NPR-A molecules bound with one molecule of ANP and, since the ANP molecule has no internal symmetry, binding to the receptor is asymmetric and occurs through two different binding sites present in each NPR-A monomer (Ogawa et al., 2004). Ularitide binds primarily to the extracellular domain of natriuretic peptide receptor-A (NPR-A) which is expressed in the heart, kidney and other organs and activates the intracellular guanylate cyclase domain of the receptor (Anker et al., 2015). Guanylate cyclases catalyze the conversion of guanosine $5^{\prime}$-triphosphate to cyclic guanosine$3^{\prime}, 5^{\prime}$-monophosphate (cGMP) causing vasodilation through vasorelaxation of smooth muscle cells and natriuresis and diuresis through inhibition of sodium reabsorption.In the treatment of stroke-associated pathologies, cationic arginine-rich peptides (CARPs) represent a new emerging class of neuroprotective agents with multimodal cytoprotective actions. Among them, NA-1, originally named TAT-NR2B9, is a lead compound being developed by NoNO for the treatment of stroke, traumatic brain injuries and subarachnoid hemorrhage and is currently in Phase 3 clinical trial. NA-1 is a 20 -mer peptide consisting in a sequence (KLSSIESDV) derived from the intracellular terminal carboxylic 
region of the $\mathrm{N}$-methyl-D-aspartate (NMDA) receptor NR2B subunit protein, fused to the cationic arginine-rich cell penetrating peptide TAT (YGRKKRRQRRR), which facilitates the passage across the blood brain barrier (Ballarin and Tymianski 2018; Meloni et al., 2020). The NR2B9 9-mer peptide was selected to inhibit the postsynaptic density protein-95 (PSD95) adaptor protein, which binds to the NR2B subunit, and thereby blocks downstream cell signalling associated with overstimulation of the NMDA receptor.

CN-105, a small 5-mer apolipoprotein E (apoE) mimetic peptide, rich of arginine residues and deriving from the receptor binding region of apoE, is currently under development by AegisCN (formerly CereNova). This peptide is in Phase 2 for the treatment of hemorrhagic stroke and intracerebral hemorrhage. CN-105 has been developed based on the amino acids present in the parent neuroprotective peptide COG133, comprising the heparin binding and LDL receptor binding domains within the apoE (Meloni et al., 2020). ApoE is a multifunctional 299-mer protein that reduces neuroinflammation and mediates adaptive responses following ischemic and traumatic brain injury. However, the intact apoE holoprotein does not cross the blood-brain-barrier (BBB) limiting its therapeutic potential. $\mathrm{CN}-105$ has the advantage of an increased CNS penetration and has demonstrated efficacy in experimental intracerebral hemorrhage, leading to an improvement of functional and histological outcomes after experimental ischemic stroke, and reducing microglial activation (Tu et al., 2017; Yeh et al., 2020).

The last peptide still in clinical trials for the treatment of cardiovascular disease through protein-protein interactions is Pemziviptadil (PB1046). PB1046 is a novel, subcutaneously injected vasoactive intestinal peptide (VIP) analogue, developed by PhaseBio Pharmaceutical that is currently tested in Phase 2 for the treatment of pulmonary arterial hypertension (PAH). VIP is a 28-mer peptide hormone that activates VPAC1 and VPAC2 receptors in the pulmonary vasculature and has been shown to relax pulmonary vascular smooth muscle, to neutralize pulmonary vasoconstrictors, and to inhibit cell proliferation (Chappe et al., 2014). The short half-life of VIP renders this peptide impractical as a pharmaceutical agent and modified versions of VIP are therefore needed to render the agent therapeutically useful (Sadeghi et al., 2015). PB1046 is 29-mer peptide linked to elastin-like polypeptide (ELP) biopolymer. The ELP component comprises structural peptide fragments that are related to the elastin protein. Such modified sequences are useful for improving important properties as absorption profile and circulating half-life (PhaseBio, 2020).

\section{NEURODEGENERATIVE DISEASES}

Neurodegenerative diseases are the result of a continuous process based on degenerative cell changes, which increasingly deteriorate over time. Aggregation of pathogenic proteins, mitochondrial dysfunction, oxidative stress, transcriptional dysfunction and apoptosis play an important role in the development of neurodegenerative disorders such as
Parkinson's disease (PD), Alzheimer's disease (AD) and Amyotrophic lateral sclerosis (ALS) (Emerit et al., 2004). Up to now, no novel disease-modifying therapies have been shown to provide significant benefits for patients who suffer from these devastating disorders. Therefore, early diagnosis and the discovery of new drugs able to bind selectively specific targets are increasingly required on the market.

Davunetide (NAP, AL-108), is an intranasally administered, 8-mer peptide fragment deriving from the activity-dependent neuroprotective protein (ADNP), actually in Phase 1 for the treatment of progressive supranuclear palsy (PSP). Davunetide has preclinical evidence for neuroprotective, neurotrophic and cognitive protective properties by promoting microtubule stabilization. (Javitt et al., 2012). The protein tubulin, constituting the microtubule backbone, was shown to be the target of NAP, recently reported as an enhancer of the interaction between microtubules and microtubule associated proteins, and microtubule polymerization under conditions of zinc intoxication (Magen and Gozes, 2014). NAP has also been reported to reduce levels of neurotoxic and pro-inflammatory factors, such as nitric oxide (NO) and tumor necrosis factor (TNF) by blocking microglial activation. The microtubules endbinding (EB) proteins have been identified as the targets of NAP, through interaction of its SIP domain. The binding of davunetide to its receptor has been recently predicted using structural alignment of EB3 to EB1-EB3 complex with another peptide ligand (MACF) (Vaisburd et al., 2015)

NLY01 (Neuraly Inc.) is a pegylated long-acting analogue of exendin-4, (Yun et al., 2018). In the Phase 1 study, NLY01 was well-tolerated, and showed a half-life three times higher than shorter-acting GLP-1R agonists, which are often limited by side effects. In 2020 the approval of an investigational new drug application (IND) to initiate a Phase $2 \mathrm{~b}$ clinical trial of NLY01 in patients with $\mathrm{AD}$ and a Phase 2 trial in patients with $\mathrm{PD}$ were announced.

In a previous study, it was shown that NLY01, through a favorable blood brain barrier penetration, binds upregulated GLP-1R, blocking pathological activation of microglia in animal models of neurodegenerative diseases, including Parkinson's (Sterling et al., 2020).

Myasthenia gravis (MG) is another serious degenerative disease, a chronic auto-immune condition in which autoantibodies attack specific proteins in the neuro-muscular junction, resulting in muscle weakness and fatigue. Zilucoplan is a small synthetic 15-mer macrocyclic peptide by UCB Pharma, currently in Phase 3 clinical trial for $\mathrm{MG}$, acting as a potent inhibitor of the terminal complement protein $\mathrm{C} 5$, with potential anti-inflammatory and cell protective activities (UCB Pharma, 2020). Upon subcutaneous administration, Zilucoplan binds to complement protein $\mathrm{C} 5$, blocking $\mathrm{C} 5$ cleavage into $\mathrm{C} 5 \mathrm{a}$ and $\mathrm{C} 5 \mathrm{~b}$ and preventing the $\mathrm{C} 5 \mathrm{~b}$-dependent assembly of the membraneattack complex (MAC). Zilucoplan also inhibits the interaction between C5b and C6, thereby further blocking MAC assembly. (Gorman et al., 2021; Duda et al.,2020).

Last but not least, GM604 (GM6, Alirinetide) is a cationic linear peptide drug that has been developed by Genervon Biopharmaceuticals and is in Phase 2 clinical trial for ALS 
disease. The peptide consists of 6 amino acids, representing a subunit of the endogenous 33-mer peptide known as "motoneuronotrophic factor" (MNTF1) (Swindell et al., 2018). Preclinical tests suggest that MNTF regulates CNS biological functions, including neuronal differentiation, axonal regeneration, reinnervation, and inflammation and apoptosis, providing both neuroprotective and neuro-regenerative therapeutic effects. GM604 is expected to have a complex mechanism of action potentially involving stimulation of multiple receptors, signaling cascades and downstream gene expression responses (Ko et al., 2017). GM604 does not selectively interact with a single target, but rather interacts with multiple receptors linked to diverse pathways. These include insulin receptor, Notch receptors one to four and smoothened frizzled class receptor. Stimulation and activation of these and other receptors by GM6 is associated with the expression of thousands of genes leading to microtubule stability, synaptic transmission and axon guidance (Genervon, 2021).

\section{BACTERIAL AND VIRAL INFECTIONS}

Infectious diseases, caused by many pathogens, including bacteria, viruses, fungi, and parasites are extremely common worldwide, although a huge number of antibiotics and antiviral drugs are available on the market. Mutation of infectious microorganisms and development of resistant strains has to be continuously faced with new medicines and for this reason innovation if this area is a need. Up today, three peptides are in clinical phase with the purpose to treat these pathologies. Due to SARS-CoV-2 virus pandemic diffusion, in the last year all anti-infective peptides entered clinical trial to verify their possible use for this infection. Anyway, since these repositioning studies are not based on a medicinal chemistry approach targeting protein receptors, reliable results are still not available. For these reasons, we decided to exclude them from this overview.

Nangibotide (LR12) is a chemically synthesized 12-mer peptide derived from residues 94 to 105 of TREM-like transcript-1 (TLT-1). LR12, launched by Inotrem, is a specific TREM-1 inhibitor, interfering in the binding of TREM-1 and its ligand (Cuvier et al., 2018; Francois et al., 2020). TREM-1 is an amplifier of the innate immune response by synergizing with tolllike receptors and is a crucial mediator of septic shock. LR12 blocks TREM-1 by binding to its ligand and provides protective effects during sepsis such as inhibiting hyper-responsiveness, organ damage and death, without causing deleterious consequences (Inotrem, 2020). The protective effects of modulating TREM-1 signaling are also evident in other models of inflammation such as pancreatitis, hemorrhagic shock and inflammatory diseases. The drug is currently in a Phase $2 \mathrm{~b}$ trial for treating septic shock and results are expected by the second half of 2021.

Reltecimod (AB103, p2TA; CD288-15) was discovered by Atox Bio as a drug candidate for the resolution of organ dysfunction or failure by attenuating the dysregulated immune

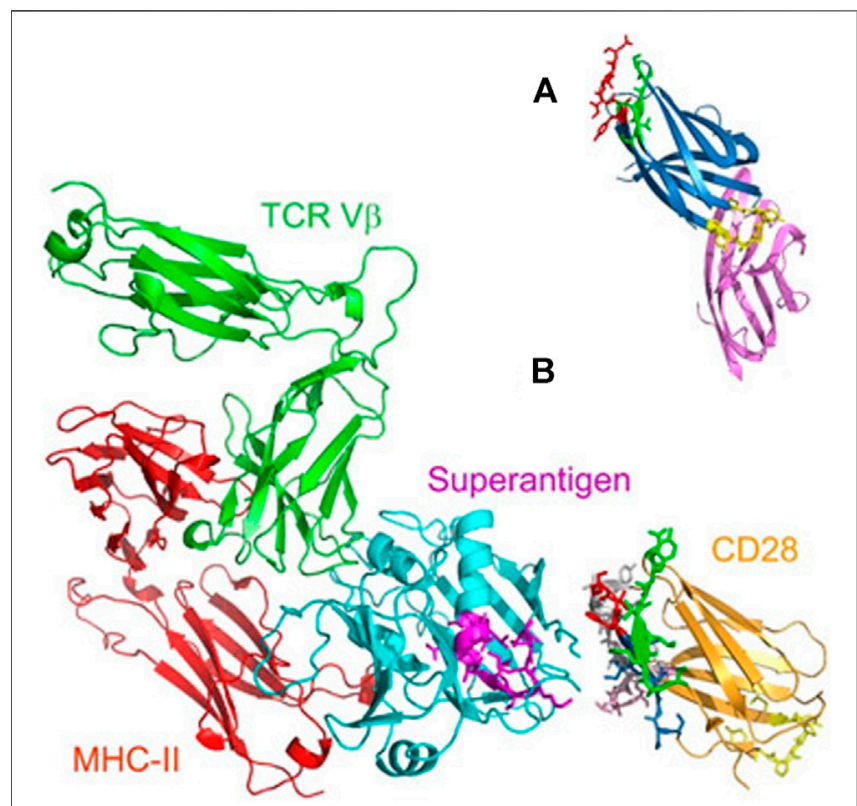

FIGURE 6 | (A) Predicted CD28 dimer interface domain (B) Model for superantigen action through binding to CD28 (adapted from Arad et al., 2011).

response frequently seen in patients with necrotizing soft tissue infection (NSTI). It is an synthetic analogue peptide with homology to the fragment $8-15$ of the T-lymphocyte receptor CD28. With its novel mechanism of action, it binds to the dimer interface of the costimulatory receptors and interferes with B7-2/ CD28 engagement expressed on T-cells, thereby modulating the acute inflammation that leads to systemic organ failure (Kaempfer, 2018). Reltecimod completed the clinical trial process and its approval by regulatory organs is currently ongoing, suggesting the launch on the market in the next future. (Pipeline Overview AtoxBio, 2021).

To understand the binding of bacterial superantigen toxins to the CD28 homodimer interface, reltecimod (SPMLVAYD) was explored, being a fragment of the CD28 dimer interface domain predicted from alignment with CTLA-4 (Figure 6A). In the available structure for $\mathrm{CD} 28$, reltecimod overlaps with the dimer interface, taking part to the complex functional superantigen binding site in CD28. The peptide competes with cell-surface CD28 for the $\beta$-strand/hinge/ $\alpha$-helix domain in the superantigen, in a site that is remote from other proteins (MHCII, TCR V $\beta$ ) binding sites (Figure 6B).

Blocking the access of a superantigen to $\mathrm{CD} 28$ is sufficient to block acute inflammation lethal toxic shock (Arad et al., 2011)

C16G2 was developed by Armata Pharmaceuticals thanks to the design of a novel platform for the treatment of bacterial infections called "Specifically Targeted Antimicrobial Peptide (STAMP) platform". STAMPs are designed by mining bacterial genomes for targeting domains that confer pathogenspecific killing activity. Therefore, C16G2, targeting S. mutans in the dental caries, was created by matching a targeting domain for effective accumulation on the $S$. mutans cell surface, as the competence-stimulating peptide $\mathrm{C} 16$ pheromone, with a killing 


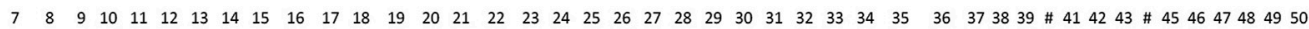

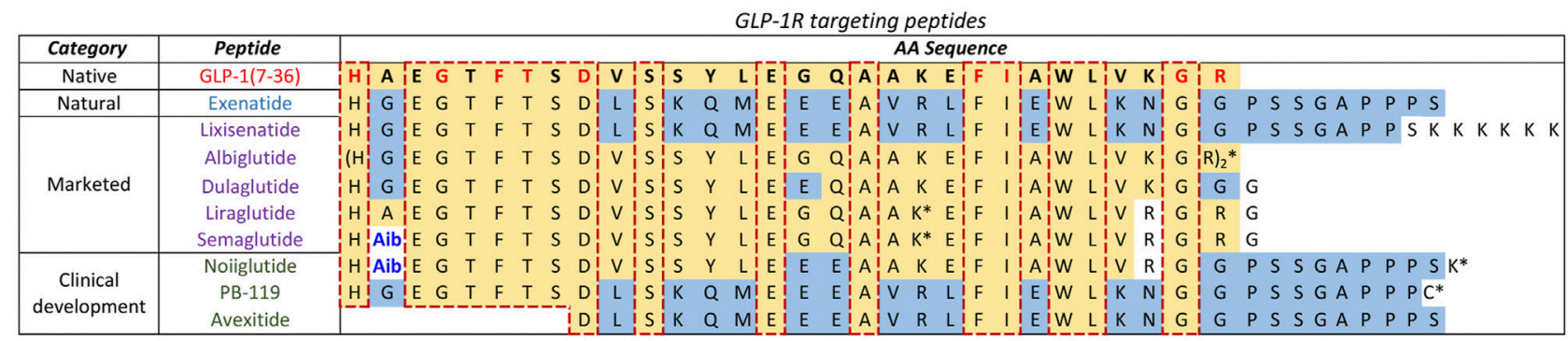

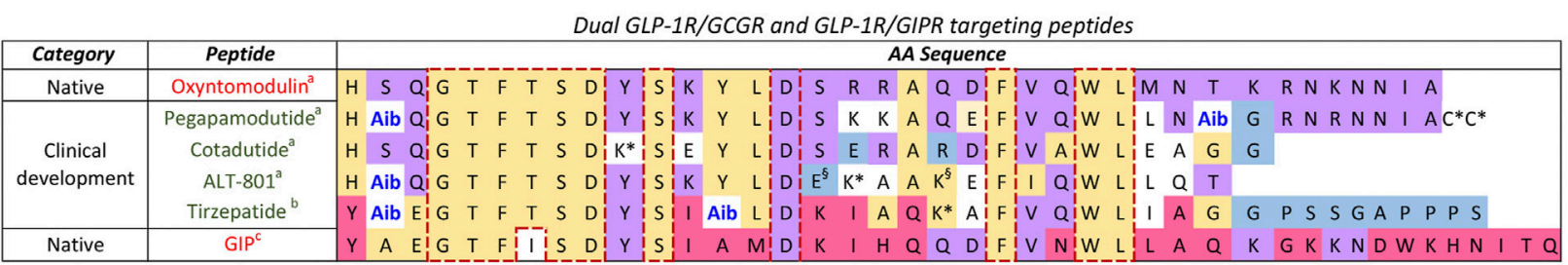

\begin{tabular}{|c|c|c|c|c|c|c|c|c|c|c|c|c|c|c|c|c|c|c|c|c|c|c|c|c|c|c|c|c|}
\hline \multirow{3}{*}{$\begin{array}{c}\text { Category } \\
\text { Native }\end{array}$} & \multirow{3}{*}{$\begin{array}{c}\text { Peptide } \\
\text { GLP-2 }\end{array}$} & \multicolumn{27}{|c|}{ GLP-2R targeting peptides } \\
\hline & & \multicolumn{27}{|c|}{ AA Sequence } \\
\hline & & $\mathrm{H}$ & A & $\mathrm{D}$ & G S & & $\mathrm{s}$ & $\mathrm{D}$ & $E$ & $M$ & $\mathrm{~N}$ & $T$ & $\mathrm{I}$ & $\mathrm{L}$ & $D N$ & $\mathrm{~N}$ & L A & $\mathrm{A}$ & $\mathrm{R}$ & D & $\mathrm{F}$ & $\mathrm{IN}$ & $\mathrm{J}$ & L I & $1 \mathrm{Q}$ & $T$ & 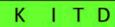 & \\
\hline Marketed & Teduglutide & $\mathrm{H}$ & G & D & G S & $\mathrm{F}$ & $s$ & D & $\mathrm{E}$ & M & $\mathrm{N}$ & T & 1 & L & D 1 & $\mathrm{~N}$ & L A & A & $\mathrm{R}$ & D & $\mathrm{F}$ & I $N$ & $\mathrm{~N} W$ & L I & I Q & $T$ & $\mathrm{~K} \quad \mathrm{I} \mathrm{T} \quad \mathrm{D}$ & \\
\hline \multirow{3}{*}{$\begin{array}{c}\text { Clinical } \\
\text { development }\end{array}$} & Apra & $\mathrm{H}$ & G & D C & G $S$ & $\mathrm{~F}$ & $S$ & D & E & Nle & $f$ & $\mathrm{~T}$ & 1 & $\mathrm{~L}$ & D & L & L A & A & $\mathrm{R}$ & D & $\mathrm{F}$ & I $N$ & $w$ & L I & I Q & $T$ & K I T D & \\
\hline & Glepaglutide & $\mathrm{H}$ & G & $\mathrm{E}$ & G $T$ & $\mathrm{~F}$ & S & $S$ & $\mathrm{E}$ & $\mathrm{L}$ & A & $\mathrm{T}$ & 1 & L & D $A$ & A & L A & A & $R$ & D & $\mathrm{F}$ & I A & $w$ & L I & I A & $T$ & K I T D & $\mathrm{DKK} \mathrm{K} \mathrm{K} \mathrm{K} \mathrm{K}$ \\
\hline & Elsiglutide & $\mathrm{H}$ & G & $\mathrm{E}$ & G $S$ & $\mathrm{~F}$ & $\mathrm{~s}$ & $\mathrm{~s}$ & $\mathrm{E}$ & $\mathrm{L}$ & $\mathrm{s}$ & T & I & L & D A & A & L A & A & $\mathrm{R}$ & D & $\mathrm{F}$ & I A & W & L I & I A & $\mathrm{T}$ & K I T D & $\mathrm{DKKKKKK}$ \\
\hline
\end{tabular}

* indicates a lipophilic side chain on the marked residue; For clarity the nature of the side chian was omitted. $\S$ indicates a lactam linkage between the side chains of the marked residues; ${ }^{a}$ Dual GLP-1R/GCGR targeting peptides; ${ }^{b}$ dual GLP-1R/GIPR targeting peptides; ${ }^{c}$ GIPR targeting peptide. AA sequence: residues colored in red = depicted from Ala scanning as important for biological activity; residues colored in blue =non natural aminoacids; highlighted in yellow: belonging to native GLP1 sequence; highlighted in blue: belonging to Exenatide sequence; highlighted in purple: belonging to Oxyntomodulin sequence; highlighted in pink: belonging to GIP sequence; highlighted in green: belonging to GLP-2 sequence

FIGURE 7 | Alignment of analogue peptides with the corresponding native ones in T2DM/obesity and SBS treatment.

domain, that is the G2 sequence as a truncated version of the broad-spectrum killing peptide novispirin G. A flexible tri-glycine sequence links the two regions. C16G2 has finished the Phase 2 clinical trials demonstrating an acceptable safety and tolerability profile of the drug and a selective reduction of S. mutans in the oral cavity. However, the company elected not to proceed to Phase 3 to seek alternatives to lower STAMP cost of goods (Kaplan et al., 2011).

\section{MISCELLANEOUS}

In this section several peptides targeting different diseases have been collected, since they cannot be classified in one of the specific pathological areas described in this review.

LJPC-401 is a synthetic human hepcidin peptide, developed by La Jolla Pharmaceutical Company for the potential treatment of conditions characterized by iron overload. In healthy individuals, hepcidin prevents excessive iron accumulation in vital organs, such as the liver and heart, where it can cause significant damage and even result in death.

The feedback circuitry between hepcidin and iron levels in the body ensures systemic iron homeostasis. Hepcidin reduces the concentration of ferroportin-1 receptor (FPN-1) on the cell surface thereby inhibiting the entry of iron into plasma.
Hepcidin binds FPN in a central cavity between the N and C domains, acting as a molecular cap to hinder the iron efflux pathway. The network of polar and hydrophobic interactions of the peptide with FPN has been assessed by evaluating decrease in binding affinity due to specific mutations (Billesbølle et al., 2020).

Binding of hepcidin to FPN-1 induces a modification in the receptor, leading to its internalization and degradation in lysosomes. In this way, the export of iron from reticuloendothelial macrophages, hepatocytes, and duodenal enterocytes is blocked (Casu et al., 2018). Hepcidin deficiency is a common feature of hereditary hemochromatosis $(\mathrm{HH})$ and LJPC-401 has completed Phase 2 clinical trials for this therapeutic target, representing a "replacement therapy" to supplement inadequate hepcidin levels (Chawla et al., 2019).

OXE-103 (Oxeia Biopharmaceuticals) is a synthetic human ghrelin, an endogenous hormone, to treat concussions/mTBI. OXE-103 freely crosses the blood-brain-barrier and helps stabilizing metabolic and energy brain dysfunction following a concussion. OXE-103 uniquely targets the hippocampus region of the brain, an important area for cognition and memory. Treatment with OXE-103 has been shown to restore normal energy metabolism, and to reduce the toxic effects of reactive oxygen species that form in low energy states. In neurons, the uncoupling protein-2 (UCP2) stabilizes mitochondria by responding to sublethal stress. The exact neuroprotective role 
of ghrelin is still unclear but UCP2-dependent mitochondrial stabilization effects in thalamic neurons have been suggested (Lopez et al., 2014). A Phase 2 study is running with the goal to reduce symptom burden with OXE103 treatment (Oxeia Biopharmaceutical, 2021).

Solnatide, is a synthetic cyclic 17-mer peptide whose molecular structure mimics the lectin-like domain (TIP) of human tumor necrosis factor (TNF) (Willam et al., 2017a, b), associated with high altitude pulmonary edema (HAPE) and adult respiratory distress syndrome (ARDS). Solnatide, also known as AP-301, has been developed by Apeptico Forschung und Entwicklung and is about to enter in Phase $2 \mathrm{~b}$ in the treatment of various pulmonary diseases. Solnatide activates the lung epithelial sodium channel $(\mathrm{ENaC})$, by directly binding to the crucial alpha-subunit of the channel and by stabilizing its open state, thus enhancing sodium ion uptake. The oligosaccharide-binding property of the TIP domain of TNF plays an important role in the mechanism by which TNF and solnatide interact with and activate $\mathrm{ENaC}$, although the exact nature of this interaction is not yet understood.

TAK639 (Takeda) is a synthetic 9-mer linear peptide which has completed phase 1 clinical trials for the treatment of Primary Open-angle Glaucoma (POAG) and intraocular pressure (IOP) (Savinainen et al., 2019). It is estimated that in 2020 more than 75 million people worldwide have suffered from ocular glaucoma; in particular, POAG is a complex optic neuropathy characterized by atrophy of the optic nerve and retinal ganglion cells and their axons, leading to irreversible blindness. Clinical evidences indicate the key role of expression and function of the natriuretic peptide network in several ocular systems, including in human trabecular meshwork. C-type natriuretic peptide (CNP) is the most potent in the class at lowering IOP in rabbits and further studies have demonstrated the presence of functional natriuretic peptide receptor-B (NPR-B) in the eyes of these animals. However, this promising treatment is affected by administration issues owing to the difficulties of atrial natriuretic peptides in penetrating the cornea to lower IOP. To overcome this drawback, TAK639 was designed as a cornea-permeable CNP derivative, exhibiting increased production and cellular concentrations of cyclic guanosine monophosphate (cGMP), able to lower IOP (Martin V. et al., 2020).

\section{CURRENT CHALLENGES AND FUTURE PERSPECTIVES IN PEPTIDES DEVELOPMENT AS THERAPEUTIC AGENTS}

The details of the industrial drug discovery and development process are normally performed under a very high degree of confidentiality. Most of the time, the structure is kept secret as long as possible and Markush structures are used in product patents, not only to enlarge the scope of the claim, but also to cover the real drug candidate formula. The structure of 11 of the 58 peptides that we have tracked down was not disclosed. In addition, for what concerns heterologous peptides most of the time also the binding mode, the hot spots of the protein-protein interaction, the modelling and the SARS are kept confidential to delay as much as possible potential competitors, since generation of "me-too" structures of peptides is quite simple.

Heterologous peptides for PPI are normally identified via a normal small molecule drug discovery approach, with the target to identify hot spots mainly via peptides library screening. Once the hit is identified, the structural changes have the target to shorten as much as possible the peptide length, to increase and stabilize the biological activity, to crystallize receptors/ligands or their fragments and to clearly identify the hot spots generating a docking model. The lead optimization to get the drug candidate will further optimize activity and selectivity, and will screen the amino acids that can be used to improve the pharmacological profile.

The approach to native/analogous peptides is completely different since, in this case, the active peptide sequence is normally well known as well as the protein-protein interaction. The critical issue is establishing the relationship of a specific PPI with a disease. Bioinformatics and a better understanding of human molecular physiology have a key role in decreasing time and cost in respect to experimental approaches for the identification of new targets (Muttenthaler et al., 2021). Starting from the native sequence, that has been already identified by nature, the challenge of the medicinal chemist is then similar to the one of heterologous peptides, with the target to file a product patent that identifies a series of new structure in a very competitive environment.

The most remarkable example of native/analogues peptides development is that of GLP-1R agonists for type- 2 diabetes and obesity. The molecules in clinical trials have been already discussed in paragraph five, however, this segment, that is by far the most important PPI in terms of potential market and industrial competition, can be used for a critical evaluation. The first in class GLP-1R agonist for type-2-diabetes mellitus, exenatide, was approved by the FDA in 2012. This molecule is the synthetic version of exendin-4, a polypeptide found in the salivary excretion of the Gila Monster, that has a $53 \%$

homology with GLP-1. While GLP-1 half-life is $1.5-5 \mathrm{~min}$, exenatide is around $2.4 \mathrm{~h}$. Since then, additional five molecules with a very high homology for GLP-1 or exenatide ( $>90 \%)$ have been approved and among them there are also the blockbusters liraglutide and semaglutide. From the alignments reported in Figure 7, it is easy to see that the amino acids that are critical for GLP-1R binding (Dods and Donnelly 2016), identified by site direct mutagenesis and Ala scanning (Knudsen and Lau 2019) have been conserved in all peptides (residues $7,10,12,13,15,28$, $29,35,36)$.

In fact, all modifications introduced in GLP-1 sequence and in the structures of dual inhibitors of GLP-1R/GIPR and GLP-1R/ GCGR have the target to increase the pharmacological profile without perturbing the binding efficiency. With the only exception of liraglutide, in all the molecules already approved and in clinical trials, the Ala8 of GLP-1, that is sensitive to dipeptidyl peptidase-4 (DPP-4), has been replaced by Gly, Aib or Ser. In addition, side chains, known to prolong half-life and potentially increase oral bioavailability, were introduced in six of 
the seven molecules in clinical trials and have been attached to amino acids that are not critical for GLP-1R binding (residues 16, $23,26,36,44,45$, and 46). From the available data semaglutide has still the record in terms of half-life (7 days). The overall development of these drugs has been largely described and the new molecules in clinical trials have followed a similar development path. From a scientific point of view, it will be interesting to monitor the evolution of dual and triple inhibitors in clinical trials to understand if these approaches will deliver any real therapeutic advantage respect to the current blockbusters.

Still serendipity can play a major role, and a typical example is Drucker's discovery of the function of GLP-2 in the intestine that ultimately resulted in the commercialization of Teduglutide for the treatment of short bowel syndrome (Drucker 2019). The natural GLP-2 has a very short half-life, $7 \mathrm{~min}$, while in Teduglutide the substitution of alanine with glycine at position two results in a peptide resistant to degradation by DPP-4 achieving a half-life of $2 \mathrm{~h}$ necessary for a daily treatment, in analogy with the GLP-1 analogues series (Marier et al., 2010). In other words, when the biological function of PPI is understood, the drug development is straightforward.

Therapeutic proteins (TP) have a consistently higher success rate than small molecules (Smietana et al., 2016). Peptides have performances similar to TP mainly because of the contribution of native/analogues and their high level of selectivity, that avoids out of target toxicity. On the other hand, heterologous peptides success rate is more similar to the one of small molecules and the target is, again, a very high level of selectivity, limiting the toxicological assessment to immunogenicity. When a market is saturated the impact of management and market considerations start to have a great impact on the attrition rate. Diabetes and obesity attracted the attention of several companies, since this is by far the most important market segment from a turnover point of view. We have described several native and analogue peptides that are targeting GLP-1R, GLP-1R/GCGR, GLP-1R/GIPR, Y2R actually in the clinic. However, there are already several peptides approved in this segment and, by the time the new ones will be approved, several potent and effective drugs will become generics. Therefore, the success rate of the molecules in the clinic will be not only related to efficacy but also by market positioning.

\section{CONCLUSION}

The PPI modulation is a fertile area for peptide development as shown by the overall peptide market and by the large pipeline discussed in this paper. The herein reported overview shows that targeting PPI represents a successful approach for a number of

\section{REFERENCES}

9 Meters Biopharma, Inc. (2021). Company Pipeline - Gastrointestinal Platform Company. Available at: https://9meters.com/pipeline/ (Accessed March 15, 2021) Acosta, A., Vasicek, T., and Brown, B. A-S. (2019). Peptide YY Pharmaceutical Formulations, Compositions and Methods. Gila Therapeutics Inc.. U.S. Patent and Trademark Office, U.S. Patent Application No US2019/0231850 different pathologies, since the network of human interactome regulates all the physiological cascade events and the related disfunctions. The availability of powerful synthetic methodologies is able to sustain medicinal chemists in the exploration of the molecular space for the design of new structures with an improved pharmacological profile. From a technological standpoint, innovation is now needed in the greening of synthetic technologies to accomplish sustainability.

Although the number of peptides entering clinical trials pathways is always increasing, a huge number of PPI are still unexplored or undisclosed. In fact, it is important to underline that, with the exception of cancer related pathologies as well as diabetes/obesity, the number of molecules in Phase 1 is very limited. The drug discovery and development process and the regulatory and market dynamics of therapeutic peptides will evolve in the near future also because of the potentially enormous impact of PPI. In conclusion, behind the PPI understanding there is the Holy Grail of protein-protein cross talk alphabet that will open up a new era in the pharmaceutical development of safe and effective drugs where the peptide modality will play a major role.

\section{AUTHOR CONTRIBUTIONS}

All authors listed have made a substantial, direct and intellectual contribution to the work, and approved it for publication.

\section{FUNDING}

This work has been developed with fundings from Alma mater Studiorum University fo Bologna (RFO)

\section{ACKNOWLEDGMENTS}

We acknowledge Stefano Mureddu, Sylwia Malinowska and Antonio Ricci from Fresenius kabi for the extensive discussions on the subject and Fresenius kabi for the grants to GM, DC, and PC.

\section{SUPPLEMENTARY MATERIAL}

The Supplementary Material for this article can be found online at: https://www.frontiersin.org/articles/10.3389/fmolb.2021.697586/ full\#supplementary-material

AltImmune (2021). Corporate Presentation 2021. Available at https://ir.altimmune. com/static-files/41e9a4ac-5982-4849-9cc4-0134553875da (Accessed June 4, 2021).

Ambery, P., Parker, V. E., Stumvoll, M., Posch, M. G., Heise, T., Plum-Moerschel, L., et al. (2018). MEDI0382, a GLP-1 and Glucagon Receptor Dual Agonist, in Obese or Overweight Patients with Type 2 Diabetes: A Randomised, Controlled, Double-Blind, Ascending Dose and Phase 2a Study. The Lancet. 391, 2607-2618. doi:10.1016/S0140-6736(18)30726-8 
Anker, S. D., Ponikowski, P., Mitrovic, V., Peacock, W. F., and Filippatos, G. (2015). Ularitide for the Treatment of Acute Decompensated Heart Failure: from Preclinical to Clinical Studies. Eur. Heart J. 36, 715-723. doi:10.1093/ eurheartj/ehu 484

Annett, S., Moore, G., Short, A., Marshall, A., McCrudden, C., Yakkundi, A., et al. (2020). FKBPL-based Peptide, ALM201, Targets Angiogenesis and Cancer Stem Cells in Ovarian Cancer. Br. J. Cancer. 122, 361-371. doi:10.1038/ s41416-019-0649-5

Arad, G., Levy, R., Nasie, I., Hillman, D., Rotfogel, Z., Barash, U., et al. (2011). Binding of Superantigen Toxins into the CD28 Homodimer Interface Is Essential for Induction of Cytokine Genes that Mediate Lethal Shock. Plos Biol. 9 (9), e1001149. doi:10.1371/journal.pbio.1001149

Arch Biopartners (2019). MetaBlock ${ }^{\mathrm{TM}}$. Available from: https://archbiopartners.com/ index.php/our-science/our-key-platforms/metablok (Accessed March 15, 2021).

Ballarin, B., and Tymianski, M. (2018). Discovery and Development of NA-1 for the Treatment of Acute Ischemic Stroke. Acta Pharmacol. Sin. 39, 661-668. doi:10.1038/aps.2018.5

Bastin, M., and Andreelli, F. (2019). Dual GIP-GLP1-Receptor Agonists in the Treatment of Type 2 Diabetes: A Short Review on Emerging Data and Therapeutic Potential. Diabetes Metab Syndr Obes. Vol. 12, 1973-1985. doi:10.2147/DMSO.S191438

Billesbølle, C. B., Azumaya, C. M., Kretsch, R. C., Powers, A. S., Gonen, S., Schneider, S., et al. (2020). Structure of Hepcidin-Bound Ferroportin Reveals Iron Homeostatic Mechanisms. Nature. 586, 807-811. doi:10.1038/ s41586-020-2668-z

Blanco, M. J., and Gardinier, K. M. (2020). New Chemical Modalities and Stratecgic Thinking in Early Drug Discovery. ACS Med. Chem. Lett. 11, 228-231. doi:10. 121/acsmedchemlett.9b00582

Boulete, I.-M., Thadi, A., Beaufrand, C., Patwa, V., Joshi, A., Foss, J. A., et al. (2018). Oral Treatment with Plecanatide or Dolcanatide Attenuates Visceral Hypersensitivity via Activation of Guanylate Cyclase-C in Rat Models. World J Gastroenterol. 24 (17), 1888-1900. doi:10.3748/wjg.v24.i17.1888

Brubaker, P. L. (2018). Glucagon-like Peptide-2 and the Regulation of Intestinal Growth and Function. Compr. Physiol. 8, 1185-1210. doi:10.1002/cphy. c170055

Canesin, G., Evans-Axelsson, S., Hellsten, R., Krzyzanowska, A., Prasad, C. P., Bjartell, A., et al. (2017). Treatment with the WNT5A-Mimicking Peptide Foxy5 Effectively Reduces the Metastatic Spread of WNT5A-Low Prostate Cancer Cells in an Orthotopic Mouse Model. PLoS ONE. 12 (9), e0184418. doi:10.1371/ journal.pone. 0184418

Capozzi, M. E., DiMarchi, R. D., Tschöp, M. H., Finan, B., and Campbell, J. E. (2018). Targeting the Incretin/Glucagon System with Triagonists to Treat Diabetes. Endocr. Rev. 39 (5), 719-738. doi:10.1210/er.2018-00117

Carmot Therapeutics Pipeline (2021). Available at: https://carmot-therapeutics.us/ pipeline/ (Accessed March 10, 2021).

Casu, C., Nemeth, E., and Rivella, S. (2018). Hepcidin Agonists as Therapeutic Tools. Blood. 131, 1790. doi:10.1182/blood-2017-11-737411

Chappe, F., Arnold, S., Ballance, J., and Chappe, V. (2014). Vip-Elp Fusion Molecules Pb1120 and Pb1046 Correct F508del-Cftr Dysfunction. Ped. Pulmon. 49, 294-295.

Chawla, L. S., Beers-Mulroy, B., and Tidmarsh, G. F. (2019). Therapeutic Opportunities for Hepcidin in Acute Care Medicine. Crit. Care Clin. 35, 357-374. doi:10.1016/j.ccc.2018.11.014

Chiquet, C., Aptel, F., Creuzot-Garcher, C., Berrod, J.-P., Kodjikian, L., Massin, P., et al. (2017). Postoperative Ocular Inflammation: a Single Subconjunctival Injection of XG-102 Compared to Dexamethasone Drops in a Randomized Trial. Am. J. Ophthalmol. 174, 76-84. doi:10.1016/j.ajo.2016.10.012

Choudhury, S. R., Babes, L., Rahn, J. J., Ahn, B.-Y., Goring, K.-A. R., King, J. C., et al. (2019). Dipeptidase-1 Is an Adhesion Receptor for Neutrophil Recruitment in Lungs and Liver. Cell. 178 (5), 1205-1221. doi:10.1016/j.cell.2019.07.017

Clemmensen, C., Finan, B., Müller, T. D., DiMarchi, R. D., Tschöp, M. H., and Hofmann, S. M. (2019). Emerging Hormonal-Based Combination Pharmacotherapies for the Treatment of Metabolic Diseases. Nat. Rev. Endocrinol. 15, 90-104. doi:10.1038/s41574-018-0118-x

Connop, B. P., Spencer, D. M. L., Singh, J., Buczek, P. D., Halbleib, C. M., Kerkow, D. E., et al. (2020). Oxyntomodulin Peptide Analog Formulations. Washington, DC: OPKO Ireland Global Hldings Ltd. U.S. Patent and Trademark Office, U.S. Patent Application No, US2020/0262887
Coskun, T., Sloop, K. W., Loghin, C., Alsina-Fernandez, J., Urva, S., Bokvist, K. B., et al. (2018). LY3298176, a Novel Dual GIP and GLP-1 Receptor Agonist for the Treatment of Type 2 Diabetes Mellitus: from Discovery to Clinical Proof of Concept. Mol. Metab. 18, 3-14. doi:10.1016/j.molmet. 2018.09.009

Craig, C. M. (2020). Avexitide for the Treatment of Hyperinsulemic Hypoglycemia. Geneva, Switzerland: Eiger Biopharmaceuticals, Inc.. World Intellectual Property Organization, PCT Patent Application No.WO2020/081534 A1

Cui, H., Zhao, C.-Y., Lv, Y., Wei, M.-J., Zhu, Y., Li, Y., et al. (2020). Safety, Tolerability and Pharmacokinetics of Single Dose Polyethylene Glycosylated Exenatide Injection (PB-119) in Healthy Volunteers. Eur. J. Drug Metab. Pharmacokinet. 45, 361-369. doi:10.1007/s13318-020-00605-9

Curtis, K. K., Sarantopoulos, J., Northfelt, D. W., Weiss, G. J., Barnhart, K. M., Whisnant, J. K., et al. (2014). Novel LHRH-Receptor-Targeted Cytolytic Peptide, EP-100: First-In-Human Phase I Study in Patients with Advanced LHRH-Receptor-Expressing Solid Tumors. Cancer Chemother. Pharmacol. 73, 931-941. doi:10.1007/s00280-014-2424-x

Cuvier, V., Lorch, U., Witte, S., Olivier, A., Gibot, S., Delor, I., et al. (2018). A FirstIn-Man Safety and Pharmacokinetics Study of Nangibotide, a New Modulator of Innate Immune Response through TREM-1 Receptor Inhibition. Br. J. Clin. Pharmacol. 84, 2270-2279. doi:10.1111/bcp.13668

Dods, R. L., and Donnelly, D. (2016). The Peptide Agonist-Binding Site of the Glucagon-like Peptide-1 (GLP-1) Receptor Based on Site-Directed Mutagenesis and Knowledge-Based Modelling. Biosci. Rep. 36, e00285. doi:10.1042/ BSR20150253

Donnelly, D. (2012). The Structure and Function of the Glucagon-like Peptide-1 Receptor and its Ligands. Br. J. Pharmacol. 166, 27-41. doi:10.1111/j.14765381.2011.01687.x

Drucker, D. J., and Nauck, M. A. (2006). The Incretin System: Glucagon-like Peptide-1 Receptor Agonists and Dipeptidyl Peptidase-4 Inhibitors in Type 2 Diabetes. The Lancet. 368, 1696-1705. doi:10.1016/S0140-6736(06)69705-5

Drucker, D. J. (2019). The Discovery of GLP-2 and Development of Teduglutide for Short Bowel Syndrome. ACS Pharmacol. Transl. Sci. 2, 134-142. doi:10. 1021/acsptsci.9b00016

Duda, P., Farzaneh-Far, R., Ma, Z., Zhu, N., Thackaberry, E., and Ricardo, A. (2020). Neurological Disease Tratment with Zilucoplan. Patent No WO/2020/ 086506. Cambridge: Ra Pharmaceuticals, Inc. doi:10.14311/tpfm.2020.008

Emani, S., Meyer, M., Palm, D., Holzmeister, J., and Haas, G. J. (2015). Ularitide: a Natriuretic Peptide Candidate for the Treatment of Acutely Decompensated Heart Failure. Future Cardiol. 11, 531-546. doi:10.2217/fca.15.53

Emanuele, N., and Emanuele, M. A. (1997). The Endocrine System: Alcohol Alters Critical Hormonal Balance. Alcohol. Health Res. World. 21 (1), 53

Emerit, J., Edeas, M., and Bricaire, F. (2004). Neurodegenerative Diseases and Oxidative Stress. Biomed. Pharmacother. 58, 39-46. doi:10.1016/j.biopha.2003. 11.004

FDA - U.S. Food and Drug Administration (2018). Available online: https://www. fda.gov/about-fda/economic-impact-analyses-fda-regulations/definition-termbiological-product-proposed-rule-preliminary-regulatory-impact-analysis

Ferrazzano, L., Corbisiero, D., Martelli, G., Tolomelli, A., Viola, A., Ricci, A., et al. (2019). Green Solvent Mixtures for Solid-phase Peptide Synthesis: A Dimethylformamide-free Highly Efficient Synthesis of Pharmaceutical-Grade Peptides. ACS Sustainable Chem. Eng. 7, 12867-12877. doi:10.1021/ acssuschemeng.9b01766

Festuccia, C., Dondi, D., Piccolella, M., Locatelli, A., Gravina, G. L., Tombolini, V., et al. (2010). Ozarelix, a Fourth Generation GnRH Antagonist, Induces Apoptosis in Hormone Refractory Androgen Receptor Negative Prostate Cancer Cells Modulating Expression and Activity of Death Receptors. Prostate. 70, a. doi:10.1002/pros.21169

Fishbane, S., Mathur, V., Germain, M. J., Shirazian, S., Bhaduri, S., Munera, C., et al. (2020). Randomized Controlled Trial of Difelikefalin for Chronic Pruritus in Hemodialysis Patients. Kidney Int. Rep. 5 (5), 600-610. doi:10.1016/j.ekir.2020. 01.006

Flanagan, C. A., and Manilall, A. (2017). Gonadotropin-Releasing Hormone (GnRH) Receptor Structure and GnRH Binding. Front. Endocrinol. 8, 274. doi:10.3389/fendo.2017.00274

Fozgerau, K., and Hoffmann, T. (2015). Peptide Therapeutics: Current Status and Future Directions. Drug Discov. Today 20, 122-128. doi:10.1016/j.drudis.2014. 10.003 
François, B., Wittebole, X., Ferrer, R., Mira, J. P., Dugernier, T., Gibot, S., et al. (2020). Nangibotide in Patients with Septic Shock: a Phase 2a Randomized Controlled Clinical Trial. Intensive Care Med. 46, 1425-1437. doi:10.1007/ s00134-020-06109-z

Gasbjerg, L. S., Gabe, M. B. N., Hartmann, B., Christensen, M. B., Knop, F. K., Holst, J. J., et al. (2018). Glucose-dependent Insulinotropic Polypeptide (GIP) Receptor Antagonists as Anti-diabetic Agents. Peptides. 100, 173-181. doi:10. 1016/j.peptides.2017.11.021

Genervon (2021). Summary of Research Evaluating GM6 Mechanisms of Action and Efficacy in ALS. Available at: https://www.genervon.com/gm6-als-moa (Accessed March 15, 2021).

Gorman, D. M., Lee, J., Payne, C. D., Woodruff, T. M., and Clark, R. J. (2021). Chemical Synthesis and Characterisation of the Complement C5 Inhibitory Peptide Zilucoplan. Amino Acids. 53, 143-147. doi:10.1007/s00726-02002921-5

Gulfidan, G., Turanli, B., Beklen, H., Sinha, R., and Arga, K. Y. (2020). Pan-cancer Mapping of Differential Protein-Protein Interactions. Sci. Rep. 10, 3272. doi:10. 1038/s41598-020-60127-x

Hall, S., Isaacs, D., and Clements, J. N. (2018). Pharmacokinetics and Clinical Implications of Semaglutide: A New Glucagon-like Peptide (GLP)-1 Receptor Agonist. Clin. Pharmacokinet. 57, 1529-1538. doi:10.1007/s40262-018-0668-z

Harb, W., Patnaik, A., Mahalingam, D., Liu, J., Wen, P. Y., Shapiro, G. I., et al. (2019). A Phase I Open Label Dose Escalation Trial Evaluating VT1021 in Patients with Advanced Solid Tumours. Ann. Oncol. 30 (Suppl. 1_5), v175-v193. doi:10.1093/annonc/mdz244.027

Hargrove, D. M., Alagarsamy, S., Croston, G., Laporte, R., Qi, S., Srinivasan, K., et al. (2020). Pharmacological Characterization of Apraglutide, a Novel LongActing Peptidic Glucagon-like Peptide-2 Agonist, for the Treatment of Short Bowel Syndrome. J. Pharmacol. Exp. Ther. 373, 193-203. doi:10.1124/jpet.119. 262238

Heickman, L. K. W., DeBoer, M. D., and Fasano, A. (2020). Zonulin as a Potential Putative Biomarker of Risk for Shared Type 1 Diabetes and Celiac Disease Autoimmunity. Diabetes/Metabolism Res. Rev. 36, e3309. doi:10.1002/dmrr.3309

Henderson, S. J., Konkar, A., Hornigold, D. C., Trevaskis, J. L., Jackson, R., Fritsch Fredin, M., et al. (2016). Robust Anti-obesity and Metabolic Effects of a Dual GLP-1/glucagon Receptor Peptide Agonist in Rodents and Non-human Primates. Diabetes Obes. Metab. 18, 1176-1190. doi:10.1111/dom.12735

Herr, D. R. (2012). Potential Use of G Protein-Coupled Receptor-Blocking Monoclonal Antibodies as Therapeutic Agents for Cancers. Int. Rev. Cel Mol. Biol. 297, 45-81. doi:10.1016/B978-0-12-394308-8.00002-9

Hu, J., Xu, Q., McTiernan, C., Lai, Y.-C., Osei-Hwedieh, D., and Gladwin, M. (2015). Novel Targets of Drug Treatment for Pulmonary Hypertension. Am. J. Cardiovasc. Drugs. 15, 225-234. doi:10.1007/s40256-015-0125-4

Hövelmann, U., Væver Bysted, B., Mouritzen, U., Macchi, F., Lamers, D., Kronshage, B., et al. (2018). Pharmacokinetic and Pharmacodynamic Character of Dasiglucagon, a Novel Soluble and Stable Glucagon Analog. Diabetes Care. 41 (3), 531-537. doi:10.2337/dc17-1402

Janeway, C. A., Jr, Travers, P., Walport, M., and Shlomchik, M. J. (2001). Immunobiology: The Immune System in Health and Disease. 5th edition. New York: Garland Science. Autoimmune responses are directed against self-antigens. Available from: https://www.ncbi.nlm.nih.gov/books/ NBK27155/ (Accessed March 15, 2021)

Javitt, D. C., Buchanan, R. W., Keefe, R. S. E., Kern, R., McMahon, R. P., Green, M. F., et al. (2012). Effect of the Neuroprotective Peptide Davunetide (AL-108) on Cognition and Functional Capacity in Schizophrenia. Schizophrenia Res. 136, 25-31. doi:10.1016/j.schres.2011.11.001

Jones, S., and Thornton, J. M. (1996). Principles of Protein-Protein Interactions. Proc. Natl. Acad. Sci. 93, 13-20. doi:10.1073/pnas.93.1.13

Inotrem (2020). Inotrem Announces the Publication of its Phase IIa Clinical Study for Nangibotide in the Treatment of Septic Shock in Peer Review Journal "Intensive Care Medicine"Available at: https://www.inotrem.com/2020/06/ 02/inotrem-announces-publication-phase-iia-clinical-study-nangibotidetreatment-septic-shock-peer-review-journal-intensive-care-medicine/ (Accessed March, 2021).

ImmuPharma (2019). Lupuzor ${ }^{\mathrm{TM}}$. Available from: https://www.immupharma.co. uk/folio/lupuzor-lupus/ (Accessed March 15, 2021).

Kaempfer, R. (2018). Bacterial Superantigen Toxins, CD28, and Drug Development. Toxins. 10, 459. doi:10.3390/toxins10110459
Kaplan, C. W., Sim, J. H., Shah, K. R., Kolesnikova-Kaplan, A., Shi, W., and Eckert, R. (2011). Selective Membrane Disruption: Mode of Action of C16G2, a Specifically Targeted Antimicrobial Peptide. Antimicrob. Agents Chemother. 55, 3446-3452. doi:10.1128/AAC.00342-11

Kaufmann, P., Cortes, J., Martin, M., Mayer, I., Vahdat, L., Pernas, S., et al. (2020). Abstract OT1-08-06: International, Phase 3 Trial: Balixafortide (A CXCR4 Antagonist) + Eribulin versus Eribulin Alone in Patients with HER2 Negative, Locally Recurrent or Metastatic Breast Cancer (FORTRESS) International, Phase 3 Trial: Balixafortide (A CXCR4 Antagonist) + Eribulin versus Eribulin Alone in Patients with HER2 Negative, Locally Recurrent or Metastatic Breast Cancer (FORTRESS). Cancer Res. 80 (4 Suppl. ment), OT1-08. doi:10.1158/1538-7445.SABCS19-OT1-08-06

Khoo, B., and Tan, T. M.-M. (2020). Combination Gut Hormones: Prospects and Questions for the Future of Obesity and Diabetes Therapy. J. Endocrinol. 246, R65-R74. doi:10.1530/JOE-20-0119

Kim, K., and Kim, K. H. (2020). Targeting of Secretory Proteins as a Therapeutic Strategy for Treatment of Nonalcoholic Steatohepatitis (NASH). Int J Mol Sci. 21 (7), 2296. doi:10.3390/ijms21072296

Kim, M. S., Ma, S., Chelariu-Raicu, A., Leuschner, C., Alila, H. W., Lee, S., et al. (2020). Enhanced Immunotherapy with LHRH-R Targeted Lytic Peptide in Ovarian Cancer. Mol. Cancer Ther. 19 (11), 2396-2406. doi:10.1158/1535-7163. MCT-20-0030

Knudsen, L. B., and Lau, J. (2019). The Discovery and Development of Liraglutide and Semaglutide. Front. Endocrinol. 10, 155. doi:10.3389/fendo.2019.00155

Ko, D., Kindy, M. S., Swindell, W. R., and Bojanowski, K. (2017). Methods of Using GM604 in Modulating ALS Disease Biomarkers Leading to Prognosis and Therapeutic Treatment for ALS diseasePatent No US 2017/0157197. Pasadena. Genevron Biopharmaceuticals, Inc

Lafferty, R. A., O’Harte, F. P. M., Irwin, N., Gault, V. A., and Flatt, P. R. (2021). Proglucagon-Derived Peptides as Therapeutics. Front. Endocrinol. 12, 689678. doi: $10.3389 /$ fendo. 2021.689678

Lau, J. L., and Dunn, M. K. (2018). Therapeutic Peptides: Historical Perspectives, Current Development Trends, and Future Directions. Bioorg. Med. Chem. 26, 2700-2707. doi:10.1016/j.bmc.2017.06.052

Lauber, T., Neudecker, P., Rösch, P., and Marx, U. C. (2003). Solution Structure of Human Proguanylin. J. Biol. Chem. 278, 24118-24124. doi:10.1074/jbc. M300370200

Lawrenson, S. B., Arav, R., and North, M. (2017). The Greening of Peptide Synthesis. Green. Chem. 19, 1685-1691. doi:10.1039/c7gc00247e

Lee, G., Lee, Y., Chang, M., Kang, S. U. K., Ryou, J.-H., Lim, J.-J., et al. (2019). P120 BBT-401 Is a Selective Pellino-1 Protein-Protein Interaction Inhibitor in Clinical Development Targeting a First-In-Class Drug for UC Treatment. Inflamm. Bowel Dis. 25 (Suppl. ment_1), S58. doi:10.1093/ibd/izy393.131

Leuchte, H. H., Baezner, C., Baumgartner, R. A., Bevec, D., Bacher, G., Neurohr, C., et al. (2008). Inhalation of Vasoactive Intestinal Peptide in Pulmonary Hypertension. Eur. Respir. J. 32, 1289-1294. doi:10.1183/09031936.00050008

Lipman, Z. M., and Yosipovitch, G. (2020). An Evaluation of Difelikefalin as a Treatment Option for Moderate-To-Severe Pruritus in End Stage Renal Disease. Expert Opin. Pharmacother. 22, 549-555. doi:10.1080/14656566. 2020.1849142

Lopez, N. E., Gaston, L., Lopez, K. R., Hageny, A. M., Putnam, J., Eliceiri, B., et al. (2014). Ghrelin Decreases Motor Deficits after Traumatic Brain Injury. J. Surg. Res. 187, 230-236. doi:10.1016/j.jss.2013.09.030

Mabonga, L., and Kappo, A. P. (2020). Peptidomimetics: A Synthetic Tool for Inhibiting Protein-Protein Interactions in Cancer. Int. J. Pept. Res. Ther. 26, 225-241. doi:10.1007/s10989-019-09831-5

Magen, I., and Gozes, I. (2014). Davunetide: Peptide Therapeutic in Neurological Disorders. Curr Med Chem. 21, 2591-2598. doi:10.2174/ 0929867321666140217124945

Marier, J.-F., Mouksassi, M.-S., Gosselin, N. H., Beliveau, M., Cyran, J., and Wallens, J. (2010). Population Pharmacokinetics of Teduglutide Following Repeated Subcutanenous Administrations in Healthy Participants and in Patients with Short Bowel Syndrome and Crohn's Disease. J.Clin. Pharmacol. 50, 36-49. doi:10.1177/0091270009342252

Martchenko, S. E., Sweeney, M. E., Dimitriadou, V., Murray, J. A., and Brubaker, P. L. (2020). Site-Specific and Temporal Effects of Apraglutide, a Novel LongActing Glucagon-like Peptide-2 Receptor Agonist, on Intestinal Growth in Mice. J. Pharmacol. Exp. Ther. 373, 347-352. doi:10.1124/jpet.119.263947 
Martin, P., Cohen, A., Uddin, S., Epelbaum, L., and Josiah, S. (2020). Randomized, Double-Masked, Placebo-Controlled Dose Escalation Study of TAK-639 Topical Ophthalmic Solution in Subjects with Ocular Hypertension or Primary Open-Angle Glaucoma. Clin Ophthalmol. Vol. 14, 885-896. doi:10. 2147/opth.s242932

Martin, V., Egelund, P. H. G., Johansson, H., Thordal Le Quement, S., Wojcik, F., and Sejer Pedersen, D. (2020). Greening the Synthesis of Peptide Therapeutics: an Industrial Perspective. RSC $A d v$. 10, 42457-42492. doi:10.1039/d0ra07204d

Massoud, R., Enose-Akahata, Y., Tagaya, Y., Azimi, N., Basheer, A., and Jacobson, S. (2015). Common $\gamma$-chain Blocking Peptide Reduces In Vitro Immune Activation Markers in HTLV-1-Associated Myelopathy/tropical Spastic Paraparesis. Proc. Natl. Acad. Sci. USA. 112 (35), 11030-11035. doi:10.1073/ pnas.1412626112

Mathiesen, D. S., Lund, A., Vilsbøll, T., Knop, F. K., and Bagger, J. I. (2020). Amylin and Calcitonin: Potential Therapeutic Strategies to Reduce Body Weight and Liver Fat. Front. Endocrinol. 11, 617400. doi:10.3389/fendo.2020.617400

Mayo, B. J., Secombe, K. R., Wignall, A. D., Bateman, E., Thorpe, D., Pietra, C., et al. (2020). The GLP-2 Analogue Elsiglutide Reduces Diarrhoea Caused by the Tyrosine Kinase Inhibitor Lapatinib in Rats. Cancer Chemother. Pharmacol. 85, 793-803. doi:10.1007/s00280-020-04040-0

McClements, L., Annett, S., Yakkundi, A., O’Rourke, M., Valentine, A., Moustafa, N., et al. (2019). FKBPL and its Peptide Derivatives Inhibit Endocrine Therapy Resistant Cancer Stem Cells and Breast Cancer Metastasis by Downregulating DLL4 and Notch4. BMC Cancer. 19, 351. doi:10.1186/s12885-019-5500-0

McGuire, D., Lane, N., Segal, N., Metyas, S., Barthel, H., Miller, M., et al. (2018). TPX-100 Leads to Marked, Sustained Improvements in Subjects with Knee Osteoarthritis: Pre-clinical Rationale and Results of a Controlled Clinical Trial. Osteoarthritis and Cartilage. 26, 243. doi:10.1016/j.joca.2018.02.502

Meloni, B. P., Blacker, D. J., Mastaglia, F. L., and Knuckey, N. W. (2020). Emerging Cytoprotective Peptide Therapies for Stroke. Expert Rev. Neurotherapeutics. 20, 887-890. doi:10.1080/14737175.2020.1788390

Min, T., and Bain, S. C. (2021). The Role of Tirzepatide, Dual GIP and GLP-1 Receptor Agonist, in the Management of Type 2 Diabetes: The SURPASS Clinical Trials. Diabetes Ther. 12, 143-157. doi:10.1007/s13300-020-00981-0

Min Xu, M., Lv, W., Zhang, Y., and Luo, X. (2019). Composition Comprisining GLP-1 Receptor Agonist and Glucagon Receptor Agonist and Application of Thereof. Washington, DC: PEGBIO Co., Ltd. U.S. Patent and Trademark Office, U.S. Patent Application No. US2019/0134161

Mordor Intelligelligence (2020). Peptide Therapeutics Market 2020-2025 Mordor Intelligence. Available at https://www.mordorintelligence.com/industryreports/peptide-therapeutics-market (Accessed June 4, 2021).

Muttenthaler, M., King, G. F., Adams, D. J., and Alewood, P. F. (2021). Trends in Peptide Drug Discovery. Nat. Rev. Drug Discov. 20, 309-325. doi:10.1038/ s41573-020-00135-8

Naimi, R. M., Hvistendahl, M., Enevoldsen, L. H., Madsen, J. L., Fuglsang, S., Poulsen, S. S., et al. (2019). Glepaglutide, a Novel Long-Acting Glucagon-like Peptide-2 Analogue, for Patients with Short Bowel Syndrome: a Randomised Phase 2 Trial. Lancet Gastroenterol. Hepatol. 4, 354-363. doi:10.1016/S24681253(19)30077-9

Nata, T., Zapata, J. C., Massoud, R., Jacobson, S., Azimi, N., and Tagaya, Y. (2015). A Multi-Cytokine Inhibitory Peptide (BNZ 132-1) that Is a Potential Therapeutic Agent for HAMTSP and Other Necrotizing Diseases. Retrovirology. 12 (Suppl. 1), O22. doi:10.1186/1742-4690-12-S1-O22

National Human Genome Research Institute NHGRI (2021). "Genetic Disorders". Available from: https://www.genome.gov/For-Patients-and-Families/GeneticDisorders (Accessed March 15, 2021).

Nestor, J. J., Zhang, X., Jaw-Tsai, S., Parkes, D. G., and Becker, C. K. (2021). Design and Characterization of a Surfactant-conjugated, Long-acting, Balanced GLP -1/glucagon Receptor Dual Agonist. Pept. Sci., e24221. doi:10.1002/pep2.24221

Neumiller, J. J., and Campbell, R. K. (2009). Liraglutide: a Once-Daily Incretin Mimetic for the Treatment of Type 2 Diabetes Mellitus. Ann. Pharmacother. 43, 1433-1444. doi:10.1345/aph.1M134

Novo Nordisk (2020). Annual Report 2020. Available at https://www.novonordisk. com/annual-report.html (Accessed June 4, 2021).

Nuijens, T., Toplak, A., Schmidt, M., Ricci, A., and Cabri, W. (2019). Natural Occurring and Engineered Enzymes for Peptide Ligation and Cyclization. Front. Chem. 7, 829. doi:10.3389/fchem.2019.00829
Ogawa, H., Qiu, Y., Ogata, C. M., and Misono, K. S. (2004). Crystal Structure of Hormone-Bound Atrial Natriuretic Peptide Receptor Extracellular Domain. J. Biol. Chem. 279, 28625-28631. doi:10.1074/jbc.M313222200

OrthoTrophix (2021). TPX-100. Available from: http://www.orthotrophix.com/ products-tpx-100.html (Accessed March 15, 2021)

Oxeia Biopharmaceuticals (2021). Available at: https://www.oxeiabiopharma.com/ what-we-do/overview (Accessed March 12, 2021).

Pahwa, R., Goyal, A., Bansal, P., and Jialal, I. (2021). Chronic Inflammation. [Updated 2020 Nov 20]. in: StatPearls [Internet]. Treasure Island, United States: StatPearls Publishing. Available from: https:/www.ncbi.nlm.nih.gov/books/ NBK493173/ (Accessed March 15, 2021).

Patil, M., Deshmukh, N. J., Patel, M., and Sangle, G. V. (2020). Glucagon-based Therapy: Past, Present and Future. Peptides. 127, 170296. doi:10.1016/j. peptides.2020.170296

Pieber, T., Tehranchi, R., Hövelmann, U., Willard, J., Plum-Moerschel, L., and Aronoson, R. (2020). Ready to Use Dasiglucagon Injection as a Fast and Effective Treatment for Severe Hypoglycaemia. Madrid, Spain: Poster Presented at the ATTD 2020 Congress

Pipeline Overview AtoxBio (2021). Available at: https://www.atoxbio.com/ pipeline/pipeline-overview/ (Accessed March 15, 2021).

Rappaport, J. A., and Waldman, S. A. (2018). The Guanylate Cyclase C-cGMP Signaling axis Opposes Intestinal Epithelial Injury and Neoplasia. Front. Oncol. 8, 299. doi:10.3389/fonc.2018.00299

Robertson, N., and Spring, D. (2018). Using Peptidomimetics and Constrained Peptides as Valuable Tools for Inhibiting Protein-Protein Interactions. Molecules. 23, 959. doi:10.3390/molecules23040959

Sadeghi, H., Dagher, S., and Turner, A. (2015). Modified Vasoactive Intestinal Peptides. U.S. Patent No 9,029,505. Washington, DC: Malvern, Phasebio Pharmaceuticals, Inc. U.S. Patent and Trademark Office, U.S. Patent No 9,029,505

Säfholm, A., Tuomela, J., Rosenkvist, J., Dejmek, J., Härkönen, P., and Andersson, T. (2008). The Wnt-5a-Derived Hexapeptide Foxy-5 Inhibits Breast Cancer Metastasis In Vivo by Targeting Cell Motility. Clin. Cancer Res. 14 (20), 6556-6563. doi:10.1158/1078-0432.CCR-08-0711

Savarirayan, R., Irving, M., Bacino, C. A., Bostwick, B., Charrow, J., Cormier-Daire, V., et al. (2019). C-type Natriuretic Peptide Analogue Therapy in Children with Achondroplasia. N. Engl. J. Med. 381, 25-35. doi:10.1056/NEJMoa1813446

Savarirayan, R., Tofts, L., Irving, M., Wilcox, W., Bacino, C. A., Hoover-Fong, J., et al. (2020). Once-daily, Subcutaneous Vosoritide Therapy in Children with Achondroplasia: a Randomised, Double-Blind, Phase 3, Placebo-Controlled, Multicentre Trial. The Lancet. 396 (10252), 684-692. doi:10.1016/S01406736(20)31541-5

Savinainen, A., Prusakiewicz, J. J., Oswald, J., Spencer, E., Lou, Z., Cohen, M. L., et al. (2019). Pharmacokinetics and Intraocular Pressure-Lowering Activity of TAK-639, a Novel C-type Natriuretic Peptide Analog, in Rabbit, Dog, and Monkey. Exp. Eye Res. 189, 107836. doi:10.1016/j.exer.2019.107836

Schneider, A., Lang, A., and Naumann, W. (2010). Fluorescence Spectroscopic Determination of the Critical Aggregation Concentration of the GnRH Antagonists Cetrorelix, Teverelix and Ozarelix. J. Fluoresc. 20, 1233-1240. doi:10.1007/s10895-010-0674-5

Serrano, J., Casanova-Martí, À., Blay, M. T., Terra, X., Pinent, M., and Ardévol, A. (2017). Strategy for Limiting Food Intake Using Food Components Aimed at Multiple Targets in the Gastrointestinal Tract. Trends Food Sci. Technology. 68, 113-129. doi:10.1016/j.tifs.2017.08.002

Shailubhai, K., Palejwala, V., Arjunan, K. P., Saykhedkar, S., Nefsky, B., Foss, J. A., et al. (2015). Plecanatide and Dolcanatide, Novel Guanylate Cyclase-C Agonists, Ameliorate Gastrointestinal Inflammation in Experimental Models of Murine Colitis. World J Gastrointest Pharmacol Ther. 6 (4), 213-222. doi:10. 4292/wjgpt.v6.i4.213

Sheetz, M., Bray, R., Tham, R. B., Jones, C., Kinsella, J., and Violante-Ortiz, R. (2017). Results of a Phase 2 Study of the Oxyntomodulin (OXM) Analogue LY2944876 in Patients with Type 2 Diabetes (T2DM). San Diego, CA: Poster presented at 77th Scientific Session American Diabetes Association; June 10

Shore, N., Tutrone, R., Efros, M., Bidair, M., Wachs, B., Kalota, S., et al. (2018). Fexapotide Triflutate: Results of Long-Term Safety and Efficacy Trials of a Novel Injectable Therapy for Symptomatic Prostate Enlargement. World J. Urol. 36, 801-809. doi:10.1007/s00345-018-2185-y 
Slim, G. M., Lansing, M., Wizzard, P., Nation, P. N., Wheeler, S. E., Brubaker, P. L., et al. (2019). Novel Long-Acting GLP-2 Analogue, FE 203799 (Apraglutide), Enhances Adaptation and Linear Intestinal Growth in a Neonatal Piglet Model of Short Bowel Syndrome with Total Resection of the Ileum. J. Parenter. Enteral Nutr. 43 (7), 891-898. doi:10.1002/jpen.1500

Sloop, K. W., Briere, D. A., Emmerson, P. J., and Willard, F. S. (2018). Beyond Glucagon-like Peptide-1: Is G-Protein Coupled Receptor Polypharmacology the Path Forward to Treating Metabolic Diseases? ACS Pharmacol. Transl. Sci. 1, 3-11. doi:10.1021/acsptsci.8b00009

Smietana, k., Siatkowski, M., and Møller, M. (2016). Trends in Clinical success Rates. Nat. Rev. Drug Discov. 15, 379-380. doi:10.1038/nrd.2016.85

Sosei Heptares (2019). Sosei Heptares Starts New Clinical Development Program First Subject Dosed in Phase I Study of HTL0030310, a Selective SSTR5 (Somatostatin 5) Receptor Agonist in Development to Treat Endocrine Disorders". Available from: https://soseiheptares.com/news/496/129/SoseiHeptares-starts-new-clinical-development-program-First-subject-dosed-inPhase-I-study-of-HTL0030310-a-selective-SSTR5-somatostatin-5-receptoragonist-in-development-to-treat-endocrine-disorders.html (Accessed June 4, 2021)

Sosne, G., and Ousler, G. W. (2015). Thymosin Beta 4 Ophthalmic Solution for Dry Eye: a Randomized, Placebo-Controlled, Phase II Clinical Trial Conducted Using the Controlled Adverse Environment $\left(\mathrm{CAE}^{\mathrm{TM}}\right)$ Model. Clin. Ophthalmol. 9, 877-884. doi:10.2147/OPTH.S80954

Sosne, G., Dunn, S. P., and Kim, C. (2015). Thymosin $\beta 4$ Significantly Improves Signs and Symptoms of Severe Dry Eye in a Phase 2 Randomized Trial. Cornea. 34 (5), 491-496. doi:10.1097/ICO.0000000000000379

Srivastava, G., and Apovian, C. (2018). Future Pharmacotherapy for Obesity: New Anti-obesity Drugs on the Horizon. Curr. Obes. Rep. 7, 147-161. doi:10.1007/ s13679-018-0300-4

Sterling, J. K., Adetunji, M. O., Guttha, S., Bargoud, A. R., Uyhazi, K. E., Ross, A. G., et al. (2020). GLP-1 Receptor Agonist NLY01 Reduces Retinal Inflammation and Neuron Death Secondary to Ocular Hypertension. Cel Rep. 33, 108271. doi:10.1016/j.celrep.2020.108271

Stumpf, M. P. H., Thorne, T., de Silva, E., Stewart, R., An, H. J., Lappe, M., et al. (2008). Estimating the Size of the Human Interactome. Proc. Natl. Acad. Sci. 105 (19), 6959-6964. doi:10.1073/pnas.0708078105

Suckfuell, M., Lisowska, G., Domka, W., Kabacinska, A., Morawski, K., Bodlaj, R., et al. (2014). Efficacy and Safety of AM-111 in the Treatment of Acute Sensorineural Hearing Loss. Otology \& Neurotology. 35 (8), 1317-1326. doi:10.1097/MAO.0000000000000466

Suzuki, R., Brown, G. A., Christopher, J. A., Scully, C. C. G., and Congreve, M. (2020). Recent Developments in Therapeutic Peptides for the Glucagon-like Peptide 1 and 2 Receptors. J. Med. Chem. 63, 905-927. doi:10.1021/acs. jmedchem.9b00835

Swindell, W. R., Bojanowski, K., Kindy, M. S., Chau, R. M. W., and Ko, D. (2018). GM604 Regulates Developmental Neurogenesis Pathways and the Expression of Genes Associated with Amyotrophic Lateral Sclerosis. Transl. Neurodegener. 7, 30. doi:10.1186/s40035-018-0135-7

Tu, T. M., Kolls, B. J., Soderblom, E. J., Cantillana, V., Ferrell, P. D., Moseley, M. A., et al. (2017). Apolipoprotein E Mimetic Peptide, CN-105, Improves Outcomes in Ischemic Stroke. Ann. Clin. Transl. Neurol. 4, 246-265. doi:10.1002/acn3.399

Vaisburd, S., Shemer, Z., Yeheskel, A., Giladi, E., and Gozes, I. (2015). Risperidone and NAP Protect Cognition and Normalize Gene Expression in a Schizophrenia Mouse Model. Sci. Rep. 5, 16300. doi:10.1038/srep16300

van den Berg, J. W., Dik, W. A., van der Zee, M., Bonthuis, F., van Holten-Neelen, C., Dingjan, G. M., et al. (2011). The $\beta$-human Chorionic GonadotropinRelated Peptide LQGV Reduces Mortality and Inflammation in a Murine Polymicrobial Sepsis Model. Crit. Care Med. 39 (1), 126-134. doi:10.1097/ CCM.0b013e3181fa3a93

van Groenendael, R., Beunders, R., Kox, M., van Eijk, L. T., and Pickkers, P. (2019). The Human Chorionic Gonadotropin Derivate EA-230 Modulates the Immune Response and Exerts Renal Protective Properties: Therapeutic Potential in
Humans. Semin. Nephrol. 39 (5), 496-504. doi:10.1016/j.semnephrol.2019. 06.009

Villoutreix, B. (2017). Structural Prediction of Human WNT-5A and Foxy-5. Figgshare. Figure Repository. doi:10.6084/m9.figshare.5354137.v1

Wang, T. T., Yang, J., Zhang, Y., Zhang, M., Dubois, S., Conlon, K. C., et al. (2019). IL-2 and IL-15 Blockade by BNZ-1, an Inhibitor of Selective $\gamma$-chain Cytokines, Decreases Leukemic T-Cell Viability. Leukemia 33, 1243-1255. doi:10.1038/ s41375-018-0290-y

Wang, Y., Lü, A., Sun, C., and Yuan, H. (2012). GLP-1 Analogues and Their Pharmaceutical Salts and Uses. Washington, DC U.S. Patent and Trademark Office, U.S. Patent Application No US2012/0196798 A1

WHO (2021). Cardiovascular Diseases. Available at: https://www.who.int/ westernpacific/health-topics/cardiovascular-diseases (Accessed March 15, 2021).

Will, S., Hornigold, D. C., Baker, D. J., Coghlan, M. P., Mesquita, M., Trevaskis, J. L., et al. (2017). Gut Check on Diabesity: Leveraging Gut Mechanisms for the Treatment of Type 2 Diabetes and Obesity. Curr. Opin. Pharmacol. 37, 10-15. doi:10.1016/j.coph.2017.07.010

Willam, A., Aufy, M., Tzotzos, S., El-Malazi, D., Poser, F., Wagner, A., et al. (2017a). TnF Lectin-like Domain Restores Epithelial Sodium Channel Function in Frameshift Mutants Associated with Pseudohypoaldosteronism Type 1B. Front. Immunol. 8, 601. doi:10.3389/fimmu.2017.00601

Willam, A., Lemmens-Gruber, R., Tzotzos, S., Fischer, B., Shabbir, W., Lucas, R., et al. (2017b). Cyclic Polypeptide for the Treatment of PHA Type 1B. Patent No WO 2017/046124. Wien: APEPTICO Forschung und Entwicklung

Yeh, C.-Y., Schulien, A. J., Molyneaux, B. J., and Aizenman, E. (2020). Lessons from Recent Advances in Ischemic Stroke Management and Targeting Kv2.1 for Neuroprotection. Int J Mol Sci. 21, 6107-6124. doi:10.3390/ijms21176107

Yun, S. P., Kam, T.-I., Panicker, N., Kim, S., Oh, Y., Park, J.-S., et al. (2018). Block of A1 Astrocyte Conversion by Microglia Is Neuroprotective in Models of Parkinson's Disease. Nat. Med. 24, 931-938. doi:10.1038/s41591-018-0051-5

Zakariassen, H. L., John, L. M., and Lutz, T. A. (2020). Central Control of Energy Balance by Amylin and Calcitonin Receptor Agonists and Their Potential for Treatment of Metabolic Diseases. Basic Clin. Pharmacol. Toxicol. 127, 163-177. doi:10.1111/bcpt.13427

Zealand Pharma (2020). Growing as a Leader in Peptide Therapeutics. Annual Report 2020. Available at https://staticl.squarespace.com/static/ 58983777d1758e28995640b4/t/604a1939ec446c62bceeeb6f/1615468866056/ Annual+report+for+2020.pdf (Accessed June 4, 2021).

Zhao, L., Zhao, Q., Lu, R., Fu, Z., Zhu, Z., Jia, J., et al. (2008). Effects of Tyroserleutide on Gene Expression of Calmodulin and PI3K in Hepatocellular Carcinoma. J. Cel. Biochem. 103, 471-478. doi:10.1002/jcb. 21409

Zimmer, R., Scherbarth, H. R., Rillo, O. L., Gomez-Reino, J. J., and Muller, S. (2013). Lupuzor/P140 Peptide in Patients with Systemic Lupus Erythematosus: a Randomised, Double-Blind, Placebo-Controlled Phase IIb Clinical Trial. Ann. Rheum. Dis. 72, 1830-1835. doi:10.1136/annrheumdis-2012-202460

Zimmermann, J., Obrecht, D., and Remus, T. (2019). Abstract A003: Antiangiogenic Activity of the CXCR4 Antagonist Balixafortide. Mol. Cancer Ther. 18 (12 Supplment), A003. doi:10.1158/1535-7163.TARG-19-A003

Conflict of Interest: The authors declare that the research was conducted in the absence of any commercial or financial relationships that could be construed as a potential conflict of interest.

Copyright (๑) 2021 Cabri, Cantelmi, Corbisiero, Fantoni, Ferrazzano, Martelli, Mattellone and Tolomelli. This is an open-access article distributed under the terms of the Creative Commons Attribution License (CC BY). The use, distribution or reproduction in other forums is permitted, provided the original author(s) and the copyright owner(s) are credited and that the original publication in this journal is cited, in accordance with accepted academic practice. No use, distribution or reproduction is permitted which does not comply with these terms. 